\title{
Marine Electromagnetic Studies of Seafloor Resources and Tectonics
}

\author{
Kerry Key
}

Received: 3 December 2010/ Accepted: 3 June 2011

(C) Springer Science+Business Media B.V. 2011

\begin{abstract}
The past decade has been a period of rapid growth for marine electromagnetic (EM) methods, predominantly due to the industrial adoption and promotion of EM as a valuable tool for characterizing offshore hydrocarbon reservoirs. This growth is illustrated by a database of marine EM publications spanning from the early developments in the 1960's to the present day; while over 300 peer-reviewed papers on marine EM have been published to date, more than half of these papers have been published within the last decade. This review provides an overview of these recent developments, covering industrial and academic use of marine EM for resource exploration and tectonic investigations, ranging from acquisition technology and modeling approaches to new physical and geological insights learned from recent data sets.
\end{abstract}

Keywords Marine electromagnetics - Magnetotelluric $\cdot$ Controlled-source electromagnetics · Electrical conductivity $\cdot$ Resources $\cdot$ Tectonics · Crust · Mantle $\cdot$ Review

\section{Introduction}

The purpose of this paper is to review the developments in marine electromagnetic (EM) methods since the previous reviews given by Baba (2005) and Edwards (2005). Other reviews covering aspects of marine EM include: Filloux (1973, 1979), Cox (1980), Fonarev (1982), Law (1983), Constable (1990), Chave et al. (1991), Brown (1994), Palshin (1996), Heinson (1999), Constable and Srnka (2007) and Constable (2010).

Before discussing the recent advances, it is worthwhile to examine the historical perspective of marine EM, spanning from the early field studies conducted in the middle of last century to the industrially dominated activity of the present day. In order to derive a metric of this growth, I searched the Web of Science's Science Citation Index Expanded for peer-reviewed papers on marine EM that were published through September, 2010. This database was then augmented with book chapters on marine EM methods,

K. Key $(\bowtie)$

Scripps Institution of Oceanography, University of California, San Diego, La Jolla, CA, USA

e-mail: kkey@ucsd.edu 
Ph.D. theses, and a few non-peer-reviewed journal articles that represent significant milestones in the commercialization of marine EM (e.g., Ellingsrud et al. 2002; Eidesmo et al. 2002). This database contains well over 300 papers, spanning from the pioneering efforts to record time-variations of the seafloor electric and magnetic fields (Wertheim 1953; Cox et al. 1964; Larsen and Cox 1966; Filloux 1967) and early theoretical considerations for controlled-source electromagnetic (CSEM) methods (Bannister 1968), to the newly published results of a large multinational magnetotelluric (MT) project to map the central Mariana subduction system (Matsuno et al. 2010). In addition to papers covering marine MT and CSEM methods, the database includes publications on sea-bottom cable studies for estimating mantle conductivity and those discussing oceanographic aspects of EM induction. Since many innovations in numerical modeling techniques for EM geophysics have been motivated by their application to marine problems, the database includes modeling algorithm papers that contain relevant marine applications or examples.

Figure 1 shows the number of papers published per year and the yearly cumulative total. The publication rate has increased significantly since marine EM's inception, reflecting the increasing utility of marine EM methods due to advances in our understanding of EM physics, improvements in instrumentation, and innovations in the numerical methods required for data interpretation. Perhaps the most significant result of this exercise is the identification of three distinct time periods of nearly linear trends in the publication rate. The early period of up to 1979 consists of only a few publications per year, mostly covering long period magnetotelluric and geomagnetic depth soundings (e.g., Filloux 1973). Around the time of the first deep-ocean marine CSEM survey described in Cox (1981) and Cox et al. (1981), the publication rate increases to several papers per year. By the year 2000, over 150 papers were published. This research pace continues until 2004, after which it quickly increases to a peak of 29 papers published in 2009 alone, resulting in the total number of papers doubling between the years 2000 and 2010.

The substantial rise around 2004 reflects the rapid uptake of CSEM methods for offshore hydrocarbon exploration. Following Statoil's and ExxonMobil's successful field trials of marine CSEM in 2000-2002 (Ellingsrud et al. 2002; Eidesmo et al. 2002; Constable and Srnka 2007), the method was quickly commercialized. The associated rise in publications illustrates how industrial activity has catalyzed a new level of research
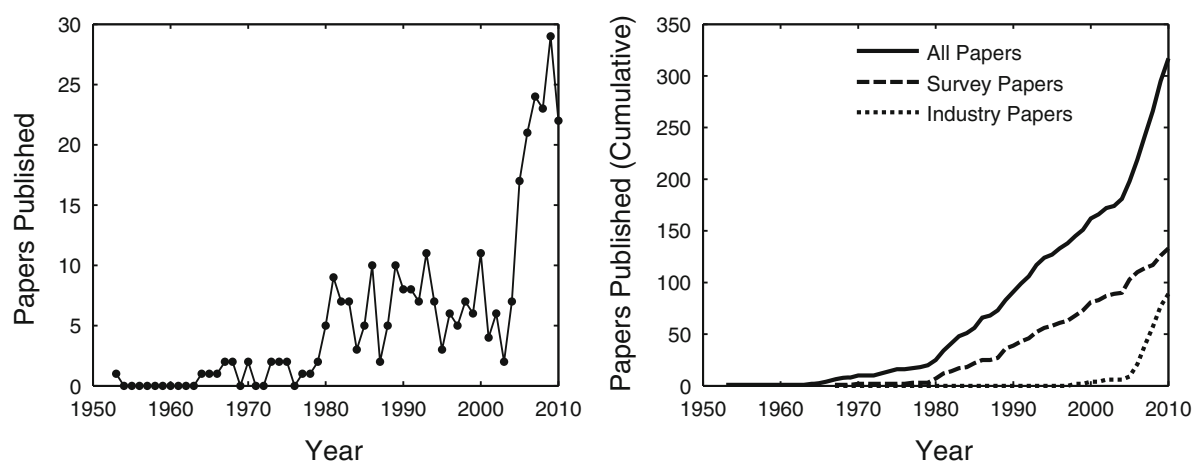

Fig. 1 The number of papers published per year on marine EM topics (left) and the cumulative total (right). Also shown are the subset of papers specifically documenting a survey data set and the subset that discuss industrial applications. Note that the values for 2010 only include papers published through September 
activity. Constable (2010) offers a recent perspective on the 10 years of industrial marine EM developments.

Figure 1 also shows cumulative totals for the subset of papers identified as documenting a specific marine EM survey (whether for industrial or tectonic applications), and the subset that specifically address industrial interests in marine EM. The industry subset shows a small number of papers from the late 1990's documenting the application of marine MT for mapping offshore basins and salt domes (e.g., Constable et al. 1998; Hoversten et al. 1998), and then quickly increases after 2004 due to the commercialization of marine EM. The trend for survey papers is nearly linear, indicating about 4 or 5 papers per year without any substantial increase occurring during the onset of industrial activity. However, this is somewhat expected given that most industry surveys are proprietary and the results are generally not made public. Consequently, the industrial subset of papers predominantly consists of methodology papers focusing on modeling and interpretation techniques.

Since the reviews by Baba (2005) and Edwards (2005), there have been well over 100 publications. It is my intention to review the main advances represented by this body of work, rather than to specifically review each individual paper. Undoubtedly I may inadvertently overlook some important works and, despite my best efforts, the database of published papers is almost certainly incomplete. However, I hope that the reader comes away from this review with a broad understanding of the recent advances, and with a road map for his/her own further investigation.

Finally, it is crucial to point out that many of the industrial advances are documented only through the (non-peer reviewed) expanded abstract databases for the annual meetings of both the Society of Exploration Geophysicists and European Association of Geoscientists \& Engineers. It is here where one can find a large number of case studies documenting marine CSEM surveys of specific offshore exploration targets. This body of work continues to grow rapidly. For example, the technical program for the 2010 SEG Annual Meeting contains about 40 abstracts on marine EM topics. While this large body of work is not included in the publications database, some significant developments will be discussed below.

\section{Marine CSEM Exploration}

Figure 2 shows a cartoon illustrating marine EM survey techniques. For a controlledsource EM application, an electric dipole transmitter system is deep-towed from a ship and passes a time-varying current (typically 500-1,000 A) between electrodes spaced apart by some distance (typically 100-300 m), producing an electromagnetic field that diffuses through the ocean, seafloor and air. As the EM field diffuses away from the transmitter, it is modified by the conductivity of the media it passes through. The resulting attenuation and phase shift of the transmitted EM field is recorded by an array of seafloor EM receivers containing electric field sensing dipoles and induction-coil magnetometers. Typical receivers for the $0.1-10 \mathrm{~Hz}$ bandwidth of most CSEM applications are based on ACcoupled electric field sensors and induction-coil magnetometers of similar design to the instrument described in Constable et al. (1998), with recent updates to modern electronics hardware such as 24-bit or greater analog-to-digital converters, data recording onto flash memory and electronic compass and tiltmeters for measuring the instrument orientation on the seafloor. 


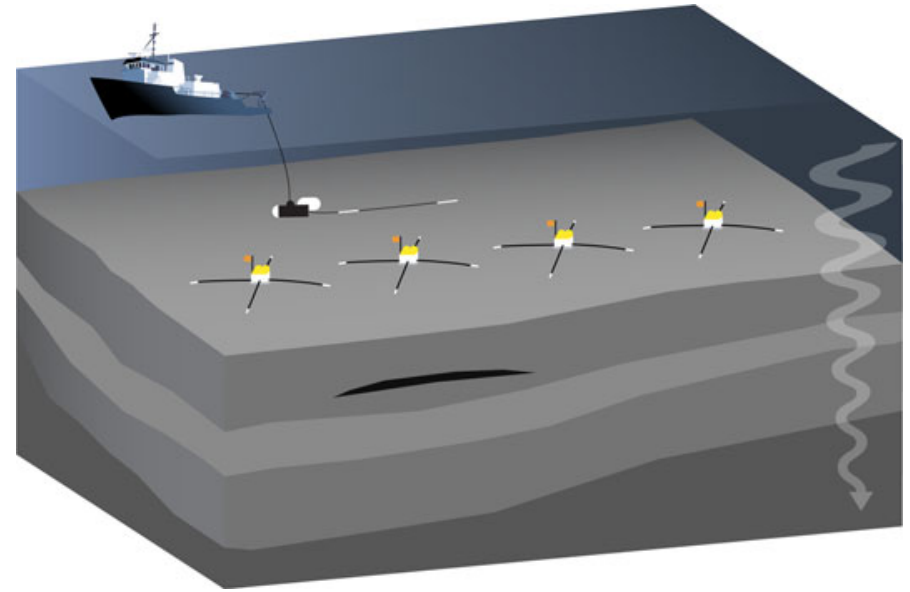

Fig. 2 A cartoon illustrating marine EM survey techniques. For the CSEM method, an EM transmitter is deep-towed behind a ship while injecting a time-varying current into the seawater. This electromagnetic signal diffuses away from the antenna, traveling through the ocean, seafloor and air, where it is modified by the conductivity of each medium. The attenuation and phase shift of the transmitted signal is recorded by an array of seafloor EM receivers containing electric field sensing dipoles (of order $10 \mathrm{~m}$ length) and inductioncoil magnetometers. For the magnetotelluric method, the seafloor receivers measure naturally occurring lowfrequency electromagnetic plane waves that diffuse into Earth

Marine CSEM was first used to measure the conductivity of the lithosphere (Cox 1981), while other early academic applications largely focused on detecting conductive magma chambers and hydrothermal systems at mid-ocean ridges (e.g., Young and Cox 1981; Evans et al. 1991; Sinha et al. 1998; MacGregor et al. 2001). Only in the past decade has it become widely recognized that the CSEM method is sensitive to thin resistive hydrocarbon reservoirs trapped in conductive sediments on the continental shelves (e.g., Edwards 2005; Constable and Weiss 2006; Um and Alumbaugh 2007). The first industrial field trials were carried out a decade ago using existing academic receiver and transmitter technologies to effectively detect the EM signature of a large reservoir offshore Angola (Ellingsrud et al. 2002; Eidesmo et al. 2002). Subsequently, the method was incorporated into the offshore hydrocarbon exploration toolkit in the course of only a few years (Constable 2010).

CSEM methods can employ electric or magnetic dipole transmitters. Theoretical 1D formulations for all magnetic and electric source geometries and a discussion of their relative merits for marine CSEM are provided in Chave and Cox (1982) and were recently revisited in the context of hydrocarbon exploration in Chave (2009).

The primary CSEM method currently being used for hydrocarbon exploration consists of a frequency-domain horizontal electric dipole that transmits to an array of independent nodal seafloor receivers that record vector electric and magnetic fields in the horizontal plane, although some receiver systems also measure the vertical field components. This independence between sources and receivers allows for the variable source-receiver offsets required for detecting conductivity from depths of only a few tens of meters down to a few kilometers beneath the seabed, but does limit the data collection to a typically sparse array of receivers.

Ziolkowski et al. (2010) present fields tests of a novel two-ship approach where the lead ship transmits to a streamer array of receivers that is deep-towed from a following ship, thereby allowing for continuous data coverage. This time-domain system has been reduced 
to a more economical single ship operation for shallow water use, with successful application to imaging a gas reservoir reported by Mattsson et al. (2010). A trade-off with the streamer configuration is that it only records inline horizontal electric fields at relatively short offsets, whereas traditional nodal receivers record the full vector electric and magnetic fields, and can be located inline and offline to great distances in order to better constrain 3D structure, although this could be partially mitigated with the streamer system by collecting additional tows on crossing lines.

A method using stationary vertical electric transmitters and receivers deployed on the seafloor has been tested by industry, but the resolution merits of this technique over the conventional deep-towed horizontal transmitter and seafloor receivers are not readily apparent (e.g., Key 2009); further study for more complex targets is warranted.

For frequency-domain EM, the transmitted signals are usually complex binary waveforms that are customized to spread the high power harmonics across the band of 0.1-10 Hz (e.g., Mittet and Schaug-Pettersen 2008), thereby allowing for improved sensitivity to both shallow and deep conductivity structures (e.g., Key 2009; Dell'Aversana and Vivier 2009). Alternatively, with time-domain EM (also called transient EM) the transmitted energy is spread continuously throughout the frequency spectrum with the use of a step on or off in the transmitter current. Cheesman et al. (1987) discuss the fundamental sensitivities of various time-domain EM transmitter and receiver combinations (electric and/or magnetic) and geometries (inline, azimuthal, vertical). The theoretical and practical merits of frequency-domain versus time-domain EM methods are a continuing controversy for both land EM and marine EM exploration, although to-date the majority of industrial offshore hydrocarbon exploration has been conducted with frequency-domain EM.

Methods for shallow surveying typically rely on a streamer array where the receiver sensors are attached by a short tether to the transmitter, enabling collection of continuous profile data and in some cases real-time data viewing aboard the ship, which could be used to adapt the survey plan as interesting features are detected. The source-receiver offsets for these systems are typically only a few tens of meters or less, and therefore limit detection to shallow targets such as gas hydrates, seafloor mounds and hydrothermal vents. Recent surveys with these systems include the use of a transient electric dipole system (Schwalenberg et al. 2005, 2010a, b), a magnetic dipole-dipole system (Evans 2007; Ellis et al. 2008; Evans et al. 2010), and DC electric dipole-dipole system (Goto et al. 2008).

Less commonly used is the magnetometric resistivity (MMR) method, consisting of a vertical electric-bipole source and a magnetic receiver (Edwards et al. 1981). Recently documented MMR surveys for tectonic studies at mid-ocean ridges are given in Evans et al. (2002) and Tada et al. (2005). The MMR technique is a simpler technology to implement since the vertical electric bipole can be formed simply by dangling electrodes over the side of a ship, thereby avoiding the technical challenges associated with deeptowing a conventional CSEM transmitter just a few tens of meters above a variable depth seafloor. However, a drawback is that the antenna bipole must be retrieved or else is dragged sideways through the water between transmission points, requiring a waiting period until the bipole settles back into the vertical position, whereas conventional deeptowed CSEM involves continuous towing and transmissions, thereby producing a much denser data set for a given amount of survey time.

Ideally, the decision of which transmitter-receiver system to use for a given survey target should be guided by careful sensitivity and resolution analyses considered in conjunction with the acquisition costs for each method. 


\subsection{Offshore Hydrocarbon Exploration}

The utility of CSEM for mapping resistive hydrocarbons is well documented throughout the recent literature. Some very accessible introductions are given in Constable and Weiss (2006), Um and Alumbaugh (2007) and Constable and Srnka (2007). The most fundamental aspect of the offshore exploration problem is that hydrocarbons are electrically resistive while porous seafloor sediments saturated with saline water are conductive. A typical reservoir is therefore a thin resistive target in a conductive background. Whereas the MT method has predominantly horizontal electric current flow and is well known to be insensitive to thin resistors, the vertical current loops created by CSEM transmitters can be interrupted by thin resistive layers, creating a detectable increase in the electromagnetic field observed on the seafloor. Since there is much less inductive attenuation in a resistive reservoir compared to the surrounding conductive sediments, the electromagnetic fields will preferentially diffuse through the reservoir. In this way, the reservoir can be viewed as a low-frequency waveguide for the diffusing EM energy (Weidelt 2007). Løseth et al. (2006) discusses some of the issues concerning the differences between wave propagation and diffusion, reinforcing that in the conductive marine environment and at the low frequencies of CSEM, the EM fields are governed by a diffusion equation.

The reservoir waveguide effect can be illustrated with a simple model study where the diffusion of the electromagnetic energy is graphically represented as the time averaged Poynting vector (e.g., Stratton 1941):

$$
\overline{\mathbf{S}}=\frac{1}{2} \operatorname{Re}\left(\mathbf{E} \times \mathbf{H}^{*}\right),
$$

where $\mathbf{E}$ and $\mathbf{H}$ are the frequency dependent electric and magnetic fields and the symbol * denotes complex conjugation. Figure 3 shows the Poynting vector direction and electric field amplitudes for the canonical 2D reservoir model, consisting of a 1,000 m ocean, a 1 ohm-m seafloor and a $5 \mathrm{~km}$ wide, 100-m thick reservoir of $100 \mathrm{ohm}-\mathrm{m}$. Computations were performed for a $0.25 \mathrm{~Hz}$ horizontal electric dipole transmitter located $50 \mathrm{~m}$ above the seabed. Due to inductive attenuation and geometric spreading, the electric field can be seen to rapidly decay with distance from the transmitter. Attenuation is most severe in the sea since it has the highest conductivity, whereas the high resistivity of the reservoir results in very little attenuation. The Poynting vectors show that the reservoir is acting to guide the EM energy along its length. The reservoir can also been seen to exhibit a galvanic shift in the electric field amplitude due to the conservation of normal (cf. tangential) current flowing across its boundaries (Um and Alumbaugh 2007).

The Poynting vectors illustrate the dominant paths of diffusion observed along the seafloor, as noted by the white numbers. In region 1 , the field predominantly reaches the seafloor by direct propagation from the transmitter through the sea. In region 2, the field has diffused through the seabed to the reservoir, then laterally across the reservoir and back up to the seabed, resulting in a stronger amplitude on the seabed than if the reservoir was absent.

At the long source-receiver offsets of region 3, the energy has traveled from the transmitter to the sea surface, through the air and then back down to the seabed, resulting in this behavior being referred to as the airwave (e.g., Constable and Weiss 2006; Nordskag and Amundsen 2007). Since the air is non-conducting, the energy only decays by geometric spreading in the air and therefore at some distance will become stronger than the energy that has traveled through the conductive ocean and seafloor. This transition occurs between regions 2 and 3, resulting in a zone of interference where upward traveling energy 


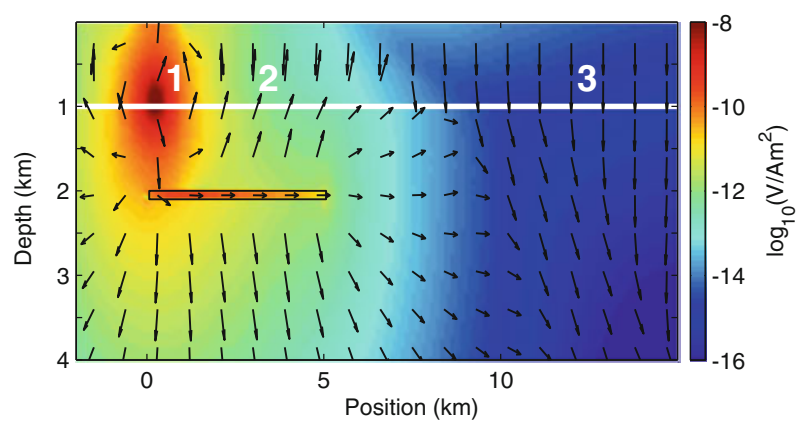

Fig. 3 Vertical cross section of the electric field polarization ellipse amplitude computed for the canonical 2D model with a $0.25 \mathrm{~Hz}$ horizontal electric dipole source positioned above the seafloor at position $0 \mathrm{~km}$. Arrows show the direction of the real part of the complex Poynting vector, illustrating the time averaged direction of energy flux throughout the model. The white line shows the seafloor and the black rectangle outlines the $100 \mathrm{~m}$ thick, $100 \mathrm{ohm}-\mathrm{m}$ reservoir

collides with the downward traveling airwave. For increasingly shallow oceans, region 3 moves closer to the transmitter, effectively saturating the much weaker signal that diffuses up from the reservoir. In shallow water $(<500 \mathrm{~m})$ where the attenuating effects of the ocean are minimal, the airwave can be significant in obscuring the weaker signal diffusing up from the reservoir. Conversely, for deep-water surveys the airwave is usually not observed since strong attenuation in the much thicker conductive ocean limits its magnitude.

\subsubsection{Dealing with the Airwave in Shallow Water}

Significant industry consideration has been given to methods that may circumvent the airwave in shallow water surveys. Amundsen et al. (2006) and Nordskag et al. (2009) consider a decomposition of the measured seafloor electromagnetic fields into upgoing and downgoing components so that the interpretation can concentrate on the relevant upward traveling energy that contains sensitivity to the reservoir. Andreis and MacGregor (2008) point out that the analytic 1D CSEM formulation contains terms corresponding to an infinite number of reflections off the sea bottom and sea surface, resulting in a strong coupling between the air, sea and seabed, and furthermore suggest it will be difficult to reliably perform the up-down separation without a priori assumption of the seabed conductivity. Instead, they propose a decomposition of the fields into TE and TM mode components since the TM mode is less affected by the air. Alternatively, since the sea surface and resistive air are the best known parameters, they can simply be included in numerical models, thereby avoiding any assumptions underlying decomposition methods. However, this direct modeling approach will not overcome the reservoir sensitivity limitation imposed by the airwave.

Weiss (2007) showed that for shallow water surveys where the airwave is strong, timedomain EM has greater sensitivity to the reservoir than frequency-domain EM at a single frequency. Li and Constable (2010) examined a suite of model sensitivity studies for timedomain EM in both shallow and deep-water depths. In defense of frequency-domain EM, Andreis and MacGregor (2008) noted that its sensitivity in shallow water is significantly improved with the use of a broad spectrum transmitter waveform, where the multiple harmonics allow for better detection of seabed conductivity variations. 


\subsubsection{Reservoir Sensitivity and Resolution}

Figure 4 shows a comparison of the inline and vertical electric fields for the canonical 2D model, its 1D equivalent, and a uniform halfspace (Orange et al. 2009). The presence of the resistive layer results in an increased amplitude and less phase lag for both the inline and vertical components, as expected since in the resistive reservoir there is much less attenuation and phase shift of the diffusing energy than in the conductive sediments. When the energy reaches the end of the $2 \mathrm{D}$ reservoir, the amplitude and phase begin to drop off rapidly due to increased attenuation in the sediments, as reflected in the responses at $5 \mathrm{~km}$ position and greater. At ranges of about $10 \mathrm{~km}$ and greater, the inline electric field for the halfspace and 2D model show signs of the airwave, which are a much smaller slope in amplitude and a transition to a constant phase shift due to the lack of inductive attenuation when the energy travels through the non-conducting air (Constable and Weiss 2006). The $1 \mathrm{D}$ response does not show any sign of the airwave to at least $15 \mathrm{~km}$ range because it is dominated by the strong component of energy diffusing up from the laterally infinite reservoir.

Orange et al. (2009) considered the utility of marine CSEM for time-lapse reservoir monitoring by examining the response change for various reservoir depletion scenarios. These studies can also be interpreted as the sensitivity to various reservoir widths and thicknesses, as shown in Fig. 5. The electric field responses show an anomaly (ratio of the $2 \mathrm{D}$ response to the halfspace response) of about 2.5 for the inline field and 5 for the vertical field. This anomaly rapidly declines as the width of the reservoir is reduced, resulting in a small amplitude anomaly of about 1.1 for both the inline and vertical fields when the reservoir is only $1 \mathrm{~km}$ wide. This demonstrates the high sensitivity to the reservoir width,
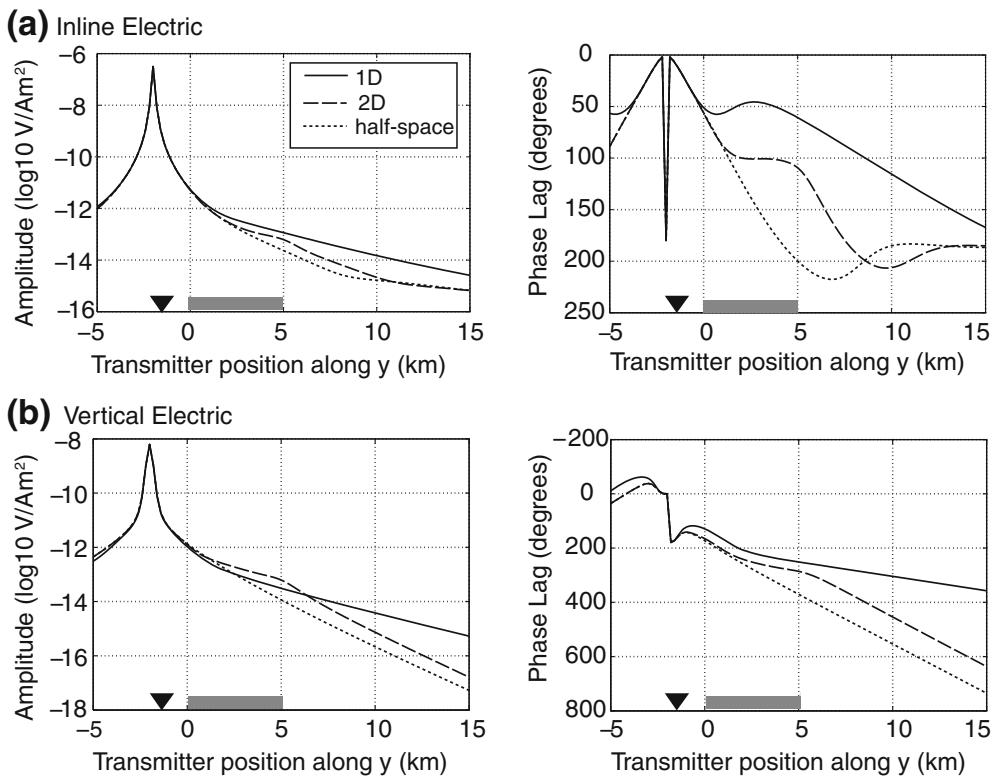

Fig. 4 Electric field responses for a halfspace and the canonical 1D and 2D reservoir models computed for a $0.25 \mathrm{~Hz}$ horizontal electric dipole at height $50 \mathrm{~m}$ above the seafloor and a single receiver located at position $-2 \mathrm{~km}$. The canonical 2D reservoir is located at $0-5 \mathrm{~km}$ position. Modified from Orange et al. (2009) 

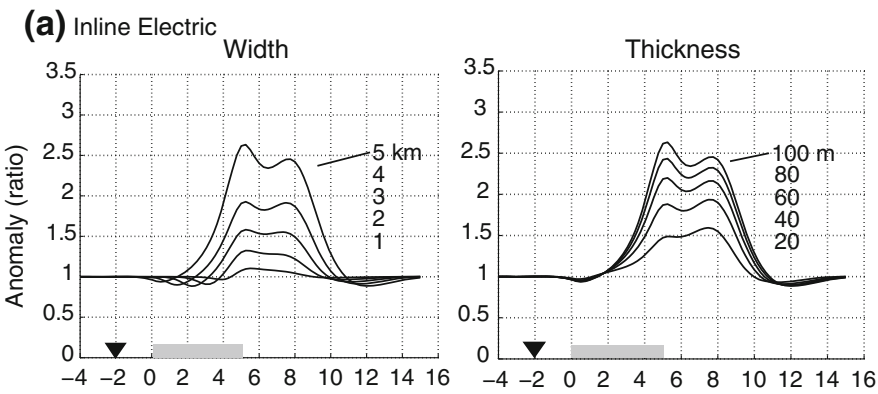

(b) Vertical Electric
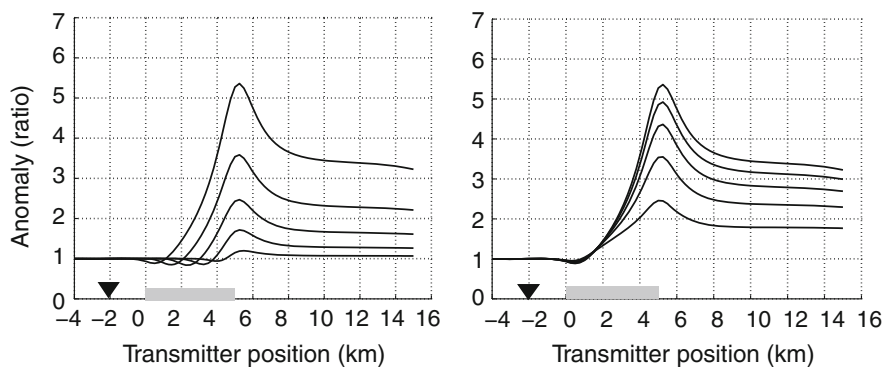

Fig. 5 Electric field anomalies generated for the canonical 2D reservoir model as a function of its width and thickness. Anomalies are computed as the ratio of the 2D response to the uniform halfspace model response. Thickness was decreased by moving the bottom up while the width was decreased by moving the left side. Modified from Orange et al. (2009)

but also points out a limitation for detecting very narrow reservoirs. In contrast, the anomalies change more slowly as the reservoir thickness is decreased. This is somewhat intuitive when thinking about the lateral propagation of the fields through the resistive reservoir. A thin but wide reservoir allows for lateral diffusion with little attenuation, resulting in a significant anomaly even for a 20 -m thick reservoir, whereas the fields attenuate quickly after reaching the end of a narrow reservoir.

Sasaki and Meju (2009) considered the CSEM response of a simple 3D reservoir consisting of a $5 \mathrm{~km}$ by $5 \mathrm{~km}$ resistor of $50 \mathrm{~m}$ thickness, $100 \mathrm{ohm}-\mathrm{m}$ resistivity and buried $1.5 \mathrm{~km}$ beneath the seabed. The largest response variation is observed for source-receiver offsets of about $6 \mathrm{~km}$, roughly in agreement with the 2D responses shown earlier. A loose rule-of-thumb for imaging reservoirs is that source-receiver offsets of about 3-6 times the reservoir depth tend to contain the peak anomaly signal, although this can vary somewhat with frequency.

Sasaki and Meju (2009) also examined how shallow small-scale heterogeneity might corrupt the ability to detect deeper targets. They show through model studies that the distortion from small-scale near-seafloor resistors is largely confined to the amplitude response and not the phase, and therefore appears to be predominantly a galvanic distortion of the electric field. Furthermore, the amplitude scatter from these is weaker than the signal from a deeper reservoir target, suggesting that shallow heterogeneities, while important to constrain, may not be a critical obstacle for deeper imaging. Darnet et al. (2007) report on a relevant example of shallow heterogeneity and seafloor topography effects observed in data collected over a thrust belt prospect in deepwater Sabah, Malaysia. Li and Constable (2007) use 2D modeling to study bathymetry distortion of CSEM data, showing significant 
variations due to airwave coupling as the water depth changes, as well as distortion from the local change in topographic slope.

A major concern for CSEM exploration is the ability to resolve a given structure. It is simple to show the data sensitivity to various structures (as exemplified by the previous model studies), whereas the data resolution concerns how well a given structure can be recovered given a finite noisy data set. Theoretical techniques for assessing the resolution of EM data are notoriously difficult due to the non-linearity and non-uniqueness of the problem (e.g., Parker 1994). However, there are simple empirical methods that can be used to gain insights into the ability to resolve a given structure.

Figure 6 shows an example of the misfit space for the canonical 1D reservoir as a function of perturbations to the reservoir thickness and resistivity. This test is performed by generating synthetic noisy data for a suite of perturbed models and then computing the root-mean-squared misfit with the true model response. For the DC resistivity case with frequency $0 \mathrm{~Hz}$, the region of low misfit is linear between the thickness and resistivity, illustrating the well-known fact that DC resistivity can only resolve the resistivity-thickness product of buried resistors. Conversely, by moving into the space of CSEM where the non-zero frequency allows for inductive effects, the low-misfit region is significantly narrower. For $0.3 \mathrm{~Hz}$ amplitude data (without phase), a maximum bound on the reservoir thickness can now be determined. For the more realistic case of multiple frequencies $(0.1$, $0.3,0.5,0.7,0.9 \mathrm{~Hz}$ ) with both amplitude and phase data, the elongated low-misfit region becomes significantly reduced in width and now much tighter bounds can be placed on the reservoir resistivity and thickness. This illustrates the benefit of multi-frequency data collection that includes the complete complex response (i.e., amplitude and phase) so that both galvanic and inductive effects are captured. Although this is a highly constrained problem since only the reservoir parameters have been perturbed and the background was held fixed, it does illustrate that, if sufficient a priori constraints on background conductivity structure are available, CSEM data could be very effective for mapping reservoir properties. For example, if the reservoir boundary depths are known a priori from the seismic interpretation and are then fixed in the conductivity model, the CSEM data might be able to accurately predict the reservoir resistivity, and consequently could be used for accurate estimates of oil or gas saturation (e.g., Hoversten et al. 2006; Key 2009).

Another resolution issue concerns the value of information in each of the possible combinations of transmitter orientations and recorded electric and magnetic field components. Key (2009) performed empirical resolution tests for each combination's ability to constrain the canonical 1D model, as shown in Fig. 7. Inline transmitter inversions were best able to recover the reservoir, regardless of which horizontal component was inverted. For all transmitter orientations, the vertical component is seen to have the least resolution, illustrating that the high $E_{\mathrm{z}}$ sensitivity shown in Figs. 4 and 5 does not correspond to a high resolution, likely due to the dominance of galvanic effects in the vertical field. No benefit in resolution is observed when inverting a combination of electric and magnetic field components together, although in practice it may be beneficial to collect all field components to mitigate potential failures of any given sensor. Other resolution tests concerning the frequency content of the data and the effects of a stratified seawater column are presented in Key (2009). Christensen and Dodds (2007) present a resolution analysis using a posteriori model covariance matrix analysis.

Weiss and Constable (2006) show Fréchet sensitivity kernel plots for a 3D resistive disk model that highlight the model regions with the greatest sensitivity for a given source and receiver configuration. An example in Fig. 8 shows the strong coupling to the resistive disk, whereas there is little sensitivity to the surrounding sediments at depth. The high 

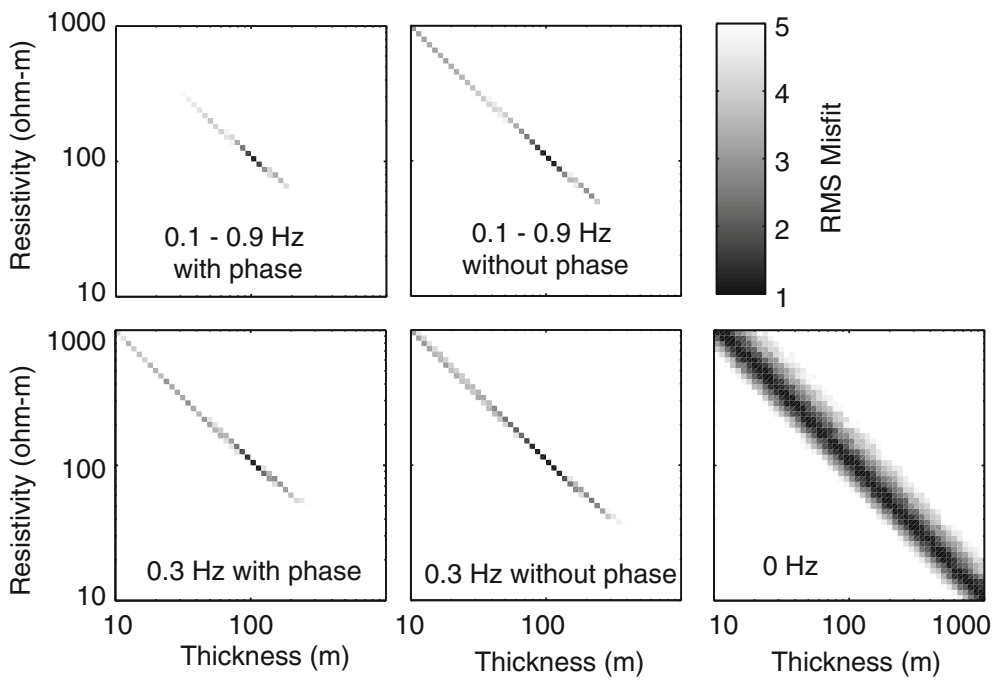

Fig. 6 Resolution study for the canonical 1D reservoir model showing the CSEM response misfit as a function of perturbations to the $100 \mathrm{~m}$ thickness and $100 \mathrm{ohm}-\mathrm{m}$ resistivity of the hydrocarbon-bearing layer. The RMS misfit was computed using $1 \%$ noisy synthetic data with variable frequency content and with/without phase information, as indicated in each plot
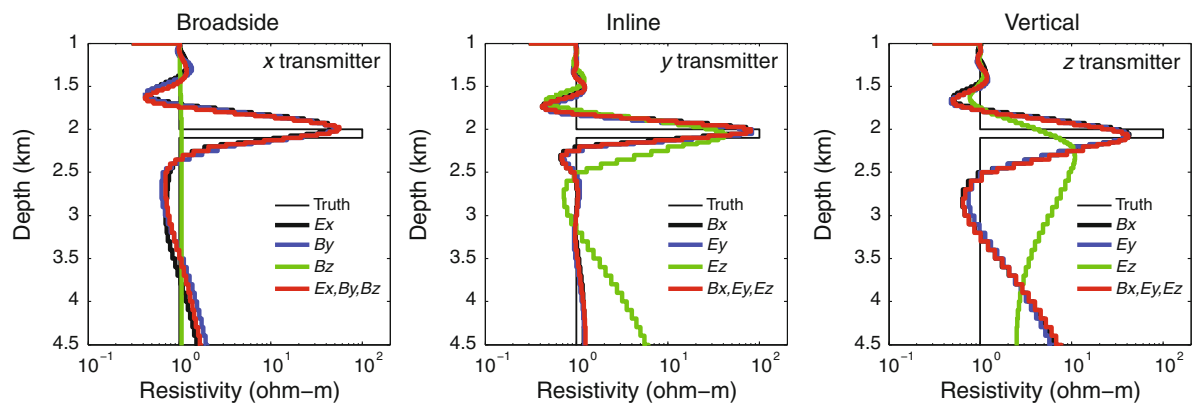

Fig. 7 A resolution comparison for the electric and magnetic field components produced by the three fundamental transmitter orientations: broadside $\mathrm{x}$, inline $\mathrm{y}$ and vertical $\mathrm{z}$. Results are shown for synthetic inversion of each component separately and all three together, as indicated in the legends. The transmission frequencies were 0.1 and $1.0 \mathrm{~Hz}$, and all models fit the data to RMS 1.0. The thin black line shows the true 1D canonical reservoir model used to generate the synthetic data. From Key (2009)

sensitivity is largely confined to the volume between the source and receiver, illustrating that CSEM is relatively immune to side-swipe issues that can plague seismic interpretation.

When planning a CSEM survey, important considerations concern the receiver and transmitter geometries required to detect a target structure, given the trade-off between the higher acquisition costs for using a large 3D array and the more economical costs for using a reduced receiver array or only a single profile. Bhuyian et al. (2010) present a comprehensive 3D sensitivity study that examines the effect of acquisition parameters for imaging a complex geometry of multiple seabed reservoirs. Figure 9 shows examples of the data sensitivity for a few crossing profiles and a full $3 \mathrm{D}$ array of transmitters and receivers. Such pre-survey model studies can be useful for optimizing the survey geometry 


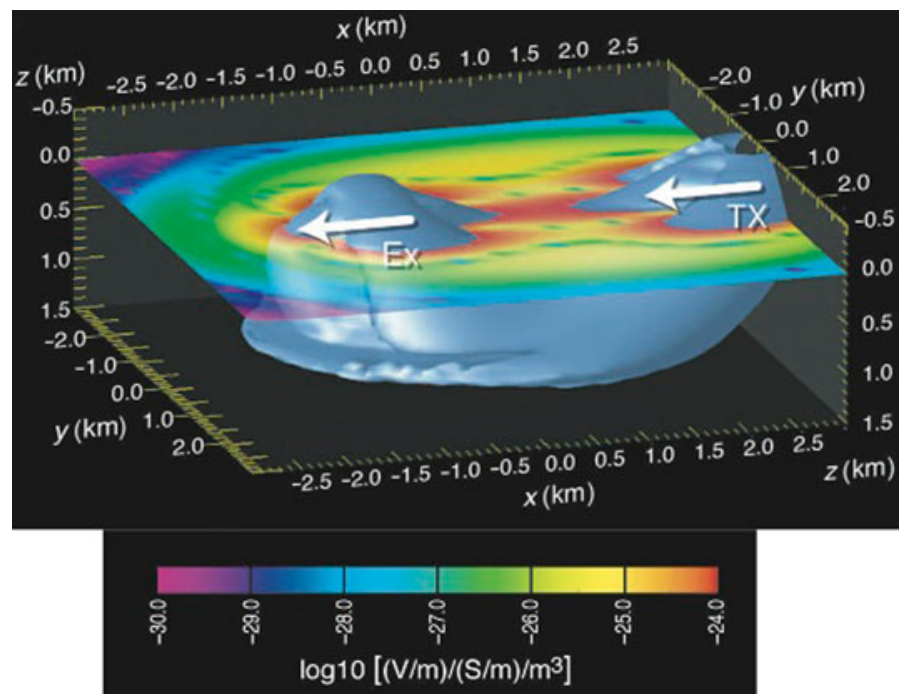

Fig. 8 Sensitivity kernel for a 4-km wide resistive disk presented in Weiss and Constable (2006). The $100-\mathrm{m}$ thick disk is located $1 \mathrm{~km}$ beneath the seabed in $1 \mathrm{ohm}-\mathrm{m}$ sediments. The $10^{-24}$ isosurface (gray) shows a strong coupling between the source, the disk and the receiver. Colored shading along the seafloor also shows that the sensitivity is largely confined to the seafloor region between the source and receivers

for maximizing target sensitivity while keeping the size of the project within the available budget. However, such studies can be highly dependent on a priori assumptions of the conductivity structure and therefore are subject to any uncertainties in these assumptions.

\subsubsection{CSEM Modeling and Inversion}

The commercial investment in marine EM exploration has motivated many innovations in modeling and inversion techniques. The recent literature is replete with model studies, as papers introducing new EM modeling approaches now routinely include relevant examples for marine CSEM. Numerical techniques in use for 2D and 3D modeling include variations of the finite difference, finite element and integral equation methods-see papers by Mulder (2006), Weiss and Constable (2006), Li and Key (2007), Plessix et al. (2007), Abubakar et al. (2008), Börner et al. (2008), Kong et al. (2008), Plessix and Mulder (2008), Singer (2008), Ueda and Zhdanov (2008), Streich (2009), Mittet (2010). While much of the software associated with these papers is proprietary, exceptions are the freely available open-source routines for 1D forward and inverse modeling described in Key (2009) (available at http://marineemlab.ucsd.edu/Projects/Occam/1DCSEM), and the 3D finite-difference code described in Weiss and Constable (2006) (available at http:// www.openem.org).

New methods for EM inversion have been developed specifically for marine EM applications. A variant of the cross-gradient regularization joint inversion approach developed for land geophysics in Gallardo and Meju (2007) was tested on marine CSEM and seismic data in Hu et al. (2009), showing that similarities in structural boundaries can be enforced through joint inversion. A boundary-model-based approach for inversion of CSEM data is presented in Li et al. (2010), building on the early sharp-boundary approach of Smith et al. (1999). Hoversten et al. (2006) and Chen et al. (2007) consider Bayesian 
(a)

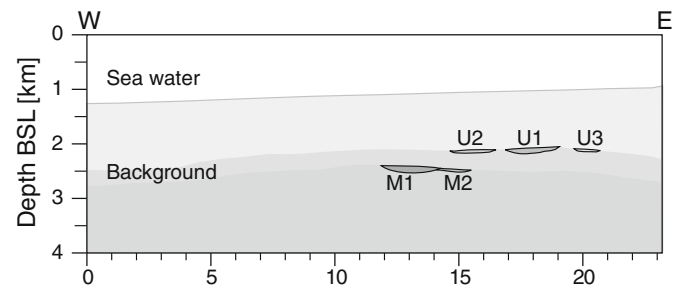

(b) $0 \mathrm{NW}$
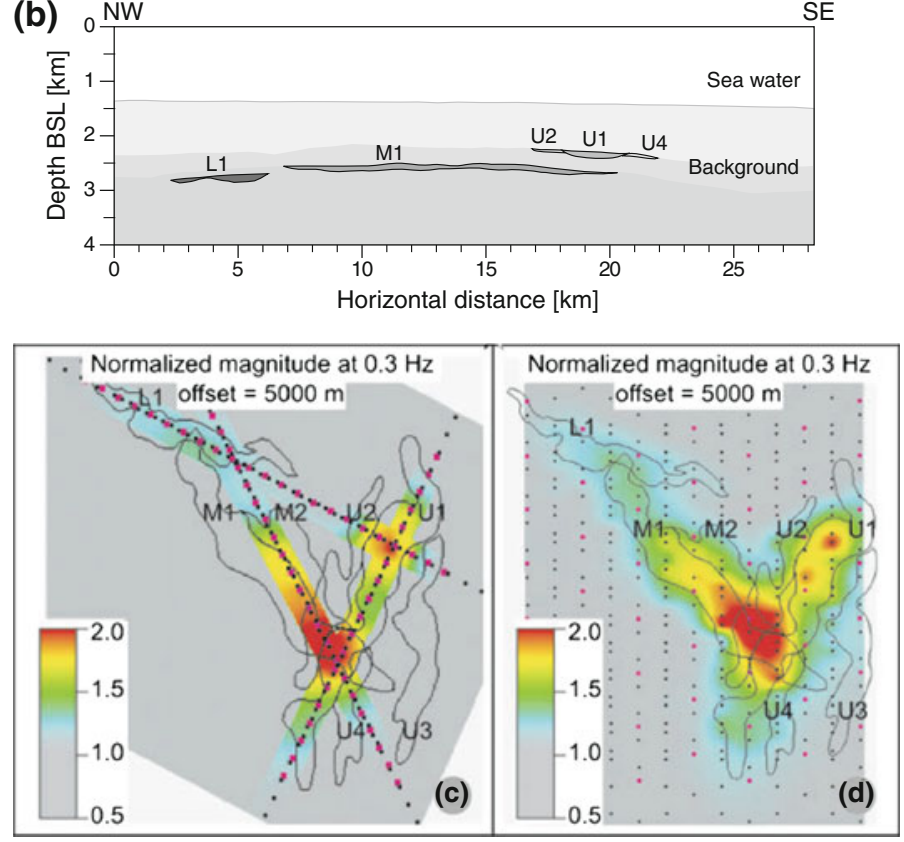

Fig. 9 CSEM survey design study from Bhuyian et al. (2010). a and b show cross-sections of the 3D forward model that includes various channel complexes filled with resistive hydrocarbons (dark regions). The map plot in (c) shows the sensitivity for three economical tow lines while (d) shows the sensitivity for the comprehensive yet more costly full 3D survey grid of transmitters and receivers

approaches to joint seismic and CSEM inversion. Bayesian inversion approaches, while demanding a vastly longer computational effort when compared to traditional gradientbased inversion methods, offer promise since they provide a measure of the model uncertainty that could be used to gauge the likelihood of a given layer's conductivity. Gradient-based 3D inversion of a full marine EM data set poses a severe computational challenge, as illustrated by Commer et al. (2008) using 32,768 processors on the IBM Blue Gene/L supercomputer to conduct a 3D inversion of marine CSEM data from a large grid of transmitters and receivers. Commer and Newman (2009) use synthetic studies to show that joint inversion of both CSEM and MT data offers better resolution of a reservoir and nearby salt body than possible when inverting either data set alone.

Fan et al. (2010) introduce a synthetic aperture CSEM method that allows for designing sources with specific radiation patterns that focus energy toward an assumed target, thereby allowing for increased target sensitivity and potentially allowing for the detection of reservoirs that are too difficult to image with conventional CSEM dipole sources. The method is accomplished as a data processing step, consisting of taking a complex linear 
combination of standard CSEM dipoles, such that the desired parts of the response are emphasized while other parts are de-emphasized. Kong et al. (2010) discuss how the spatial wavenumber of the fields observed on the seabed can be related to the diffusion through an idealized thin resistive layer, thereby yielding a data interpretation technique that is independent of numerical modeling efforts.

\subsubsection{Uncertainties in Orientations and Positions}

Because CSEM receivers free-fall to the seafloor, their orientations need to be recorded by electronic compasses. However, compasses sometimes fail to record or can be contaminated by magnetized portions of the receiver, thereby giving unreliable orientation estimates. Mittet et al. (2007) present a technique to solve for inline receiver orientations by rotating the data until the crossline electric field component is minimized. Key and Lockwood (2010) offer a general method based on an orthogonal Procrustes rotation analysis technique imbedded into an inversion, thereby allowing for the full 3D orientation of the receiver to be estimated for both inline and offline receivers. Another issue concerning the reliability of CSEM data is the position of the sources and receivers. Weitemeyer (2008) considers an inversion technique where the relative positions and orientations of all the survey equipment are inverted for simultaneously along with the inversion for seabed conductivity. This method could be used in cases where navigation data are either unavailable or are unreliable.

\subsubsection{Anisotropy}

Sediment conductivity can be anisotropic due to a variety of causes. Two exploration relevant cases are grain-scale anisotropy in shales due to mineral alignment, and the macroscopic anisotropy produced by thinly layered strata of varying conductivity, resulting in the vertical resistivity typically being larger than the horizontal resistivity. The effects of anisotropic conductivity can be important for CSEM exploration, where broadside data have been shown to be sensitive to the sediment horizontal conductivity while inline data are predominantly sensitive to the vertical reservoir resistivity and the horizontal overburden resistivity (Løseth and Ursin 2007; Kong et al. 2008). Ramananjaona et al. (2011) show the sensitivity patterns for an anisotropic seabed and demonstrate synthetically that isotropic inversion of anisotropic data can produce severe artifacts in inversion models, making anisotropic interpretation vital in such situations. Newman et al. (2010) present case studies demonstrating anisotropic conductivity effects in field data from the North Sea and offshore Brazil, showing the overburden to be up to three times more resistive in the vertical direction for the North Sea data (Fig. 10).

\subsubsection{Reservoir Monitoring}

An area of potential future growth for CSEM is time-lapse reservoir monitoring. Lien and Mannseth (2008) and Orange et al. (2009) present model studies documenting small but detectable changes in frequency-domain CSEM for various reservoir production scenarios. Ziolkowski et al. (2010) examine time-lapse repeatability for real and synthetic timedomain CSEM data over the North Sea Harding field. Another possibility for monitoring is to place either a source or receiver inside a borehole to allow for better coupling with the reservoir. Kong et al. (2009) consider a seafloor transmitter to borehole receiver scenario, 

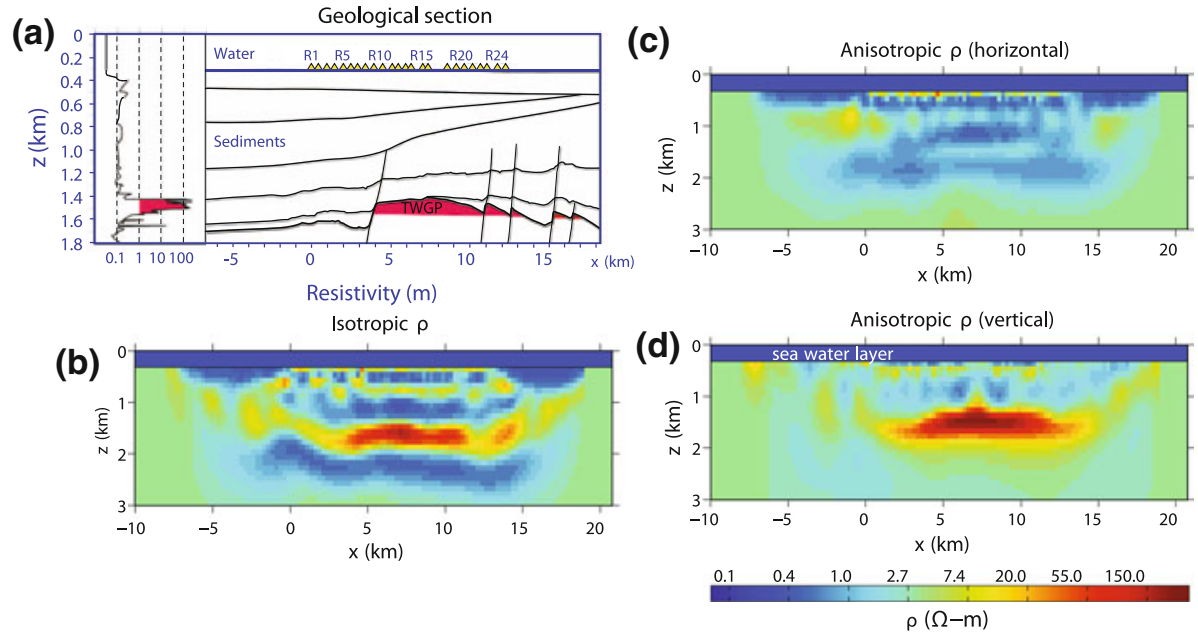

Fig. 10 A comparison of isotropic and anisotropic inversions of CSEM data collected at the Troll West Gas Province (TWGP). Modified from Newman et al. (2010)

concluding that the conductive steel casing of the borehole will degrade the vertical resolution of TM mode measurements but will not degrade the horizontal resolution.

\subsubsection{The Scarborough Survey}

Myer et al. (2010a) present initial results from the first fully academic marine CSEM and MT survey of a hydrocarbon reservoir, consisting 144 CSEM and MT receiver data sets and $800 \mathrm{~km}$ of CSEM tows, collected at the Scarborough gas field on the Exmouth Plateau, about $250 \mathrm{~km}$ offshore northwestern Australia (Fig. 11). The goals of this work are to advance knowledge on how marine EM methods can be used for hydrocarbon exploration, to test new instrument systems, and to provide a comprehensive exploration quality data set that will be released into the public domain for testing new processing and modeling algorithms.

\subsection{Mapping Gas Hydrates and Shallow Structure}

CSEM methods have recently been demonstrated to be effective for in-situ mapping of seafloor gas hydrates. Consisting of a methane molecule encased by a water lattice, gas hydrates are stable under pressure at water depths in excess of $300 \mathrm{~m}$ and ocean temperatures of around $0^{\circ} \mathrm{C}$. The hydrate stability zone is typically confined to the upper hundred meters of the seafloor due to the rise in temperature associated with the geothermal gradient. Because hydrates are thought to exist on the continental shelves nearly worldwide, their role in the global methane flux and associated climate change is thought to be significant. Hydrates can pose a significant drilling hazard for conventional hydrocarbon exploration, but also represent a potential energy resource. Seismic reflection data are able to detect hydrates as a nearly continuous reflection known as a bottom simulating reflector (BSR), interpreted to be the impedance contrast associated with the base of the hydrate stability field where free gas exists below and hydrate exists above. However, 


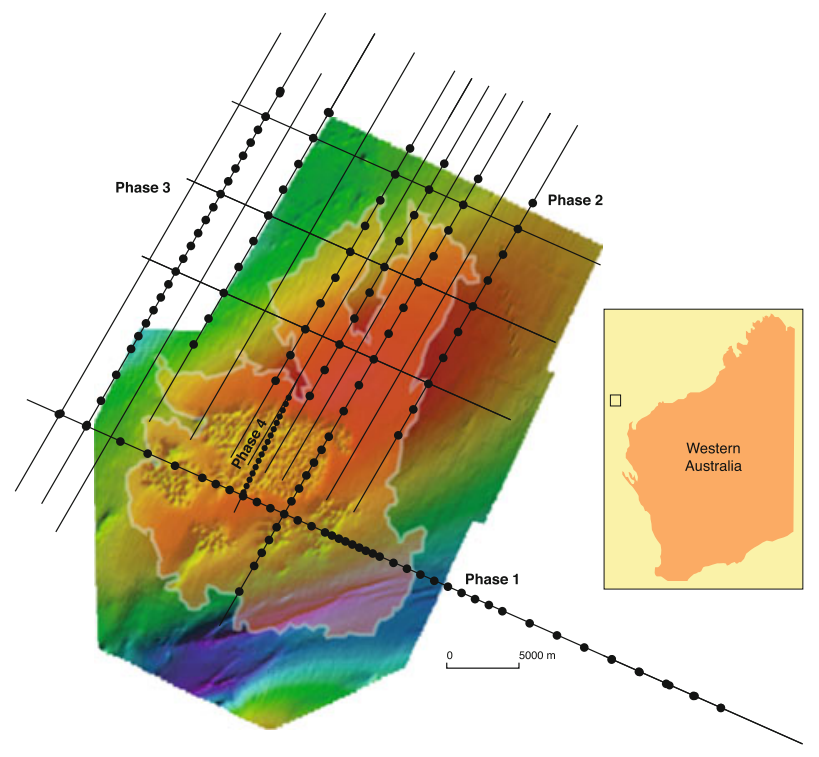

Fig. 11 The Scarborough gas field marine EM survey conducted by the Scripps Institution of Oceanography, consisting of 144 CSEM and MT receiver data sets and $800 \mathrm{~km}$ of CSEM transmitter tows collected on the Exmouth Plateau, about $250 \mathrm{~km}$ offshore northwestern Australia. Colors show the seafloor bathymetry variations and the white outline denotes the seismically imaged reservoir boundaries. From Myer et al. (2010a)

seismic methods are less sensitive to the bulk hydrate existing above the BSR, whereas the high electrical resistivity of hydrates makes them a suitable target for EM methods.

Recent field tests of the CSEM method have indicated a strong sensitivity to the presence of hydrate (Schwalenberg et al. 2005, 2010a, b; Weitemeyer et al. 2006; Weitemeyer 2008). Zach and Brauti (2009) discuss the CSEM sensitivity to shallow gas hydrates from the perspective of how it might corrupt the imaging of deeper hydrocarbon reservoirs. Similar to the study by Sasaki and Meju (2009), they show that phase data is less perturbed by shallow resistors than amplitude data, likely due to the lack of inductive effects in these electromagnetically thin resistors.

Figure 12 shows an example of a 2D model obtained from inversion of 25 sites of CSEM data collected at Hydrate Ridge, offshore Oregon (Weitemeyer et al. 2006; Weitemeyer 2008). The inversion model, computed with a proprietary inversion code (Abubakar et al. 2008), shows a shallow resistive zone in the west (left) that crosses the BSR depths, suggesting a significant presence of both free gas and gas hydrates in this region. These data were collected with a conventional CSEM system used for deep exploration; hence it is sensitive to both shallow and deep structure, as indicated by the structural variability in the $2 \mathrm{D}$ inversion model.

Schwalenberg et al. (2010a, b) report results from applying a fixed-offset time-domain CSEM system to map gas hydrate bearing sediments in two locations offshore New Zealand. Because this system only has source-receiver offsets of 172 and $275 \mathrm{~m}$, its depth sensitivity is limited in comparison with a conventional nodal CSEM system. Figure 13 shows an example of high resistivity zones imaged at Opouawe Bank, Hikurangi Margin, New Zealand (Schwalenberg et al. 2010a). Goto et al. (2008) present successful results from using a deep-towed DC resistivity streamer system to map methane hydrates in the 


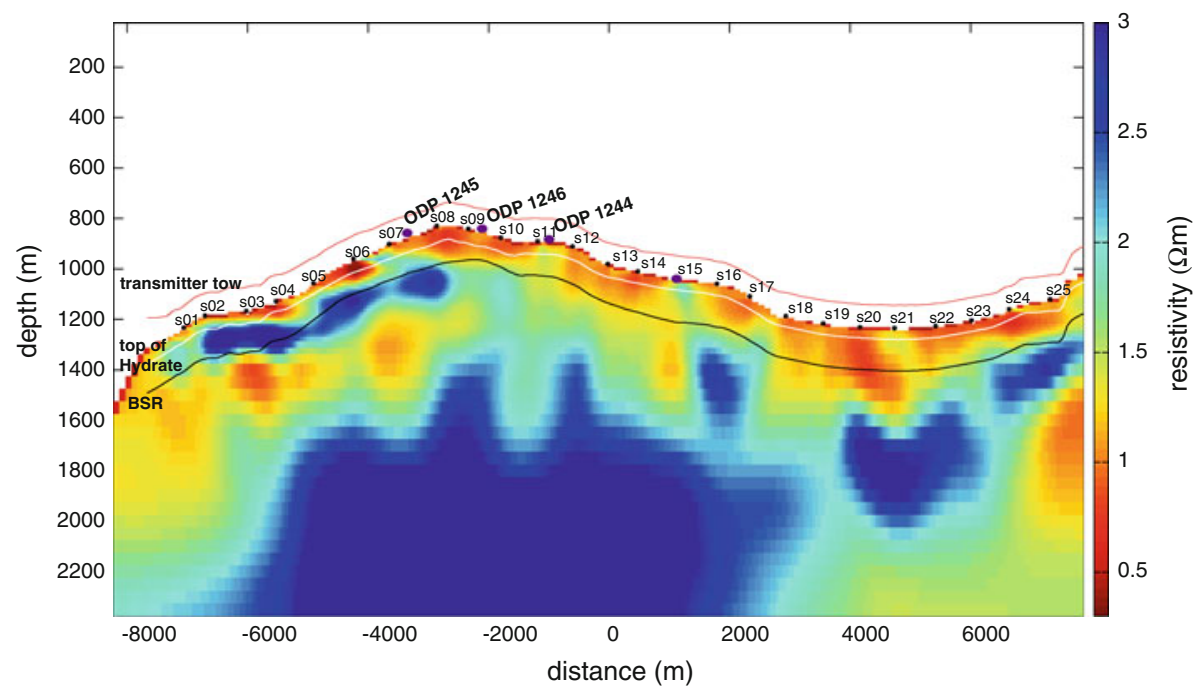

Fig. 12 A 2D inversion model obtained from CSEM data collected at Hydrate Ridge, offshore Oregon using an array of 25 seafloor receivers and a towed EM transmitter. The transmitter positions are marked by the red line and receivers are labeled black dots. The estimated top of hydrate is marked by the white line and the seismic bottom simulating reflector is marked by a black line. From Weitemeyer (2008)

Japan Sea. Given the compelling results from both the nodal and fixed-offset systems, it seems likely that the use of marine EM methods for hydrate mapping will see significant growth in the coming years.

Evans (2007) and Ellis et al. (2008) describe a fixed-offset magnetic dipole-dipole survey to investigate mud mounds in Atwater Valley, northern Gulf of Mexico. The mounds are thought to be associated with gas hydrates and/or authigenic carbonates due to bright acoustic reflections from the seafloor. Unexpectedly, the mounds are observed to be significantly more conductive than the surrounding seafloor, as indicated by the high apparent porosities shown in Fig. 14. The high conductivity is attributed to the effects of raised temperatures and high pore fluid salinities, suggesting deep fluid advection beneath the mounds due to faulting associated with the underlying salt domes that are ubiquitous throughout the region (Ellis et al. 2008). Evans (2007) presents the case for using shallow CSEM techniques on the continental margins for a variety of purposes, including sediment characterization, facies mapping and the evaluation of groundwater discharge.

Scholl and Edwards (2007) propose a method using a vertical borehole time-domain EM source with seafloor receivers in order to map shallow resistive structure and present several model studies documenting the sensitivity and resolution of the method.

\section{Marine Magnetotelluric Exploration}

The magnetotelluric (MT) method uses naturally occurring low-frequency plane waves that diffuse into the seabed (Fig. 2). Measurements of both the electric and magnetic fields on the seafloor are used to derive the Earth's frequency dependent impedance, which is then forward and inverse modeled to estimate the seabed conductivity. 
(a)
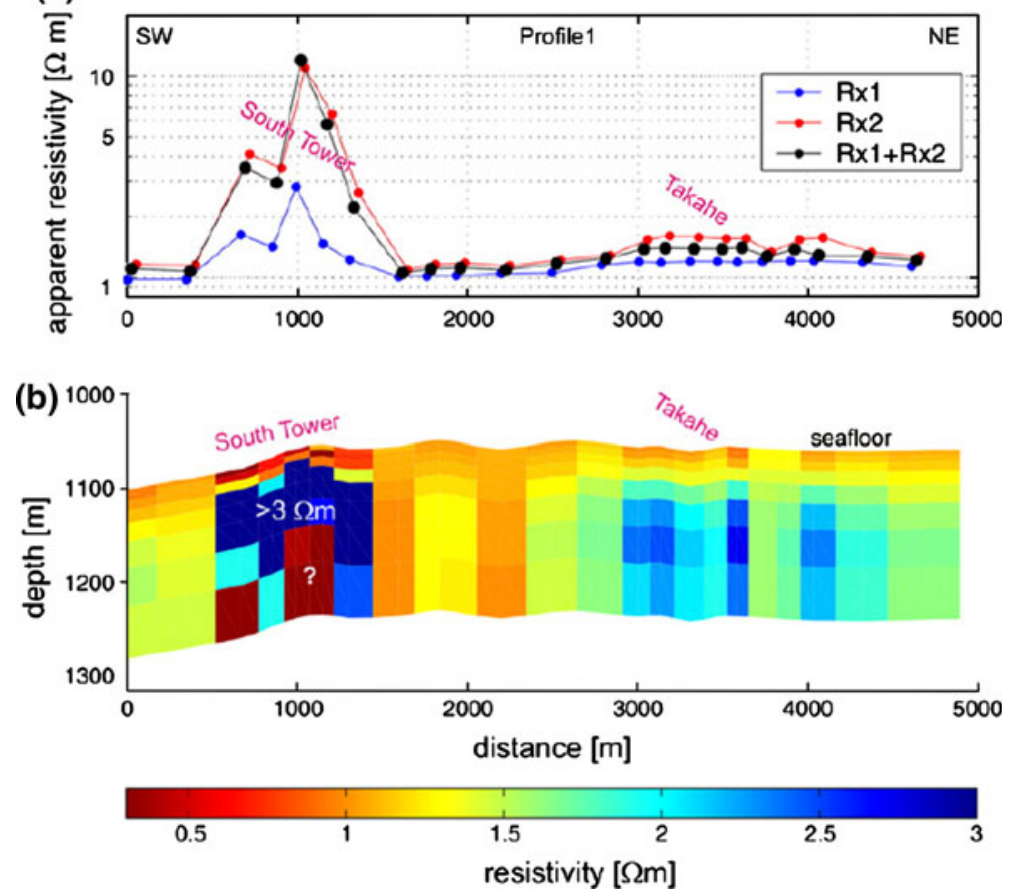

Fig. 13 Fixed-offset CSEM survey of a gas hydrate zone at Opouawe Bank, Hikurangi Margin, New Zealand. a Apparent resistivity profiles derived from the two fixed-offset receiving channels, showing a strong increase over the South Tower. b 1D inversion results stitched together, showing a strong increase in resistivity at the gas seep at South Tower and a moderate increase over the seep at Takahe. From Schwalenberg et al. (2010a)

The two main types of marine MT instruments in use are long-period systems applied for mantle studies, and broadband systems used for exploring shallower targets on both the continental shelves and in the deep ocean. Conventional long-period MT instruments typically use flux-gate magnetometers and DC electric field amplifiers to obtain MT responses at periods of a few hundred seconds to about $100,000 \mathrm{~s}$, thereby offering sensitivity to several hundred kilometers into the mantle. Recording times are typically on the order of several months, requiring separate deployment and recovery cruises (e.g., Seama et al. 2007). A specialized long-period MT system has been deployed in the northwest Pacific as a geomagnetic observatory, currently with a remarkable 2000 days of recordings achieved through multiple redeployments (Toh et al. 2006a, 2010).

Broadband MT instrumentation is identical to the systems that are used for CSEM exploration, utilizing induction-coil magnetometers and AC-coupled electric field amplifiers that can detect the much lower amplitude fields present at shorter periods (e.g., Constable et al. 1998). Broadband systems have a bandwidth of about $0.1-10,000 \mathrm{~s}$, offering sensitivity to targets in the crust and upper-most mantle. The shortest periods measurable are limited by attenuation in the conductive ocean, while the longest periods are limited by the recording time. Figure 15 shows three examples of broadband data collected in different water depths and using different recording times. The Mahogany 


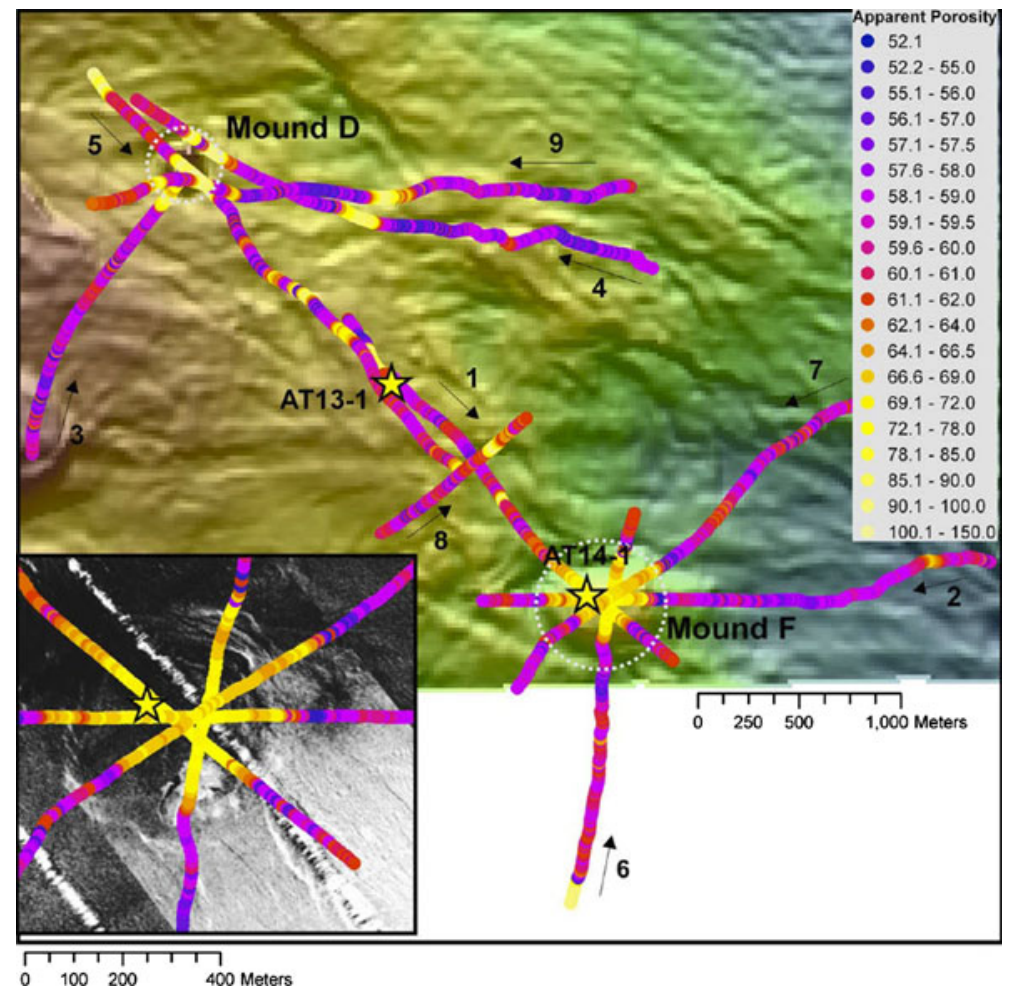

Fig. 14 EM survey of seafloor mounds at Atwater Valley, northern Gulf of Mexico. Colored dots show high apparent porosity variations associated with the mounds. The inset shows a close-up view of data collected across mound F with sidescan data as a background. From Ellis et al. (2008)

Prospect data obtains a bandwidth of $0.1-300 \mathrm{~s}$ using $16 \mathrm{~h}$ recording in $100 \mathrm{~m}$ water depth. The Gemini Prospect data bandwidth of $1-2,000 \mathrm{~s}$ results from 2 days recording in 1,000 m ocean depth. The recently collected SERPENT data used 19 days recording in 2,900 m water depth, resulting in a bandwidth of 10-20,000 s.

Broadband systems are advantageous when many MT stations are required. Since deployments are as short as a few days to weeks, an extensive survey can be performed in a single cruise. When only a few days recording are needed, instruments can be deployed and redeployed several times, offering the chance to collect 10's to 100's of stations during a single month-long survey (e.g., Key et al. 2005; Myer et al. 2010a). Disadvantages of the broadband system include the limited ability to record very long-period MT responses and hence a lack of sensitivity to the greater depths that are possible with long-period systems. For example, at Gemini Prospect on the continental shelf in the Gulf of Mexico, the $6 \mathrm{~km}$ of highly porous $1 \mathrm{ohm}-\mathrm{m}$ sediments limit the MT data sensitivity to about 10-20 km depth (e.g., Key 2003; Key et al. 2006). Conversely, broadband data collected in the deep ocean over resistive seafloor can be sensitive to 100-200 km depth (e.g., Key and Constable 2002). Since the induction coils only measure changes in the magnetic field, broadband systems require an auxiliary compass sensor that records the instrument's geomagnetic orientation on the seafloor. 

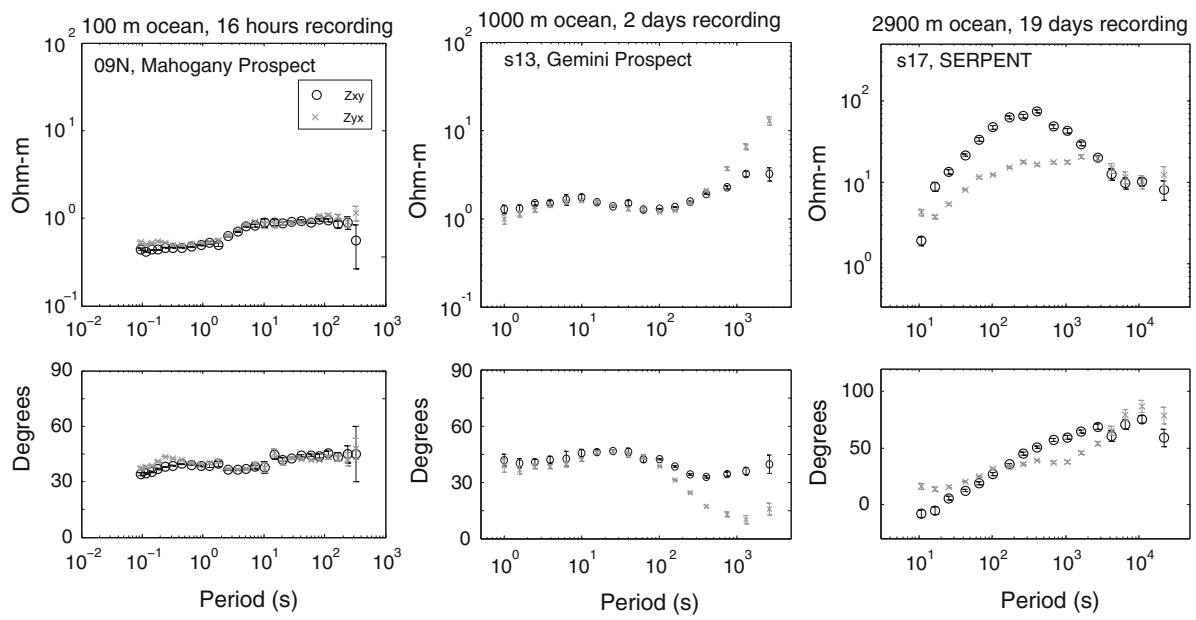

Fig. 15 Examples of variable bandwidth MT responses obtained with the broadband receiver technology described in Constable et al. (1998). Left 0.1-300 s response obtained with $16 \mathrm{~h}$ recording in $100 \mathrm{~m}$ water at Mahogany Prospect, Gulf of Mexico. Middle 1-3,000 s response obtained with 2 days recording in 1,000 m water at Gemini Prospect, Gulf of Mexico (Key et al. 2006). Right 10-20,000 s response obtained with 19 days recording in $2,900 \mathrm{~m}$ water for the SERPENT project offshore Nicaragua (http://marineemlab. ucsd.edu/Projects/SERPENT)

\subsection{Topographic and Coast Effect Distortions}

The conductivity contrast between the conductive ocean and the resistive seafloor and coastline is well known to distort marine MT measurements. These distortions arise from a combination of galvanic and inductive effects that operate on local, regional and global scales (e.g., Fischer and Weaver 1986; Heinson and Constable 1992; Heinson and Lilley 1993; Key 2003; Schwalenberg and Edwards 2004). Constable et al. (2009) report on broadband MT data collected in the San Diego Trough offshore California that exhibit extreme distortions. They observe TE apparent resistivity cusps and negative phases, and a strongly depressed TM mode apparent resistivity (Fig. 16). They show through 2D model studies that the TE distortion arises from a steepening of the magnetic field near the coastline so that the horizontal magnetic field passes through zero amplitude at a characteristic frequency, thereby imparting an upward pointing cusp in the apparent resistivity. The TM mode distortion is attributed to a predominantly galvanic effect arising from charge build-up on the local bathymetry and regional coastline.

One approach to mitigating these distortions is to directly include bathymetry in numerical models. An early method applicable to long-period MT sounding is the use of thin-sheet modeling to simulate the effects of the variable ocean thickness and coastline (e.g., Heinson and Lilley 1993). Baba and Seama (2002) created a finite-difference approach that uses conductivity averaging in the cells that straddle the seafloor topography. Li et al. (2008) used a finite-difference approximation that permits discrete sloping boundaries inside the model cells. Key and Weiss (2006) and Franke et al. (2007) developed finite element algorithms that use unstructured triangular meshes which readily conform to seafloor topography. These direct modeling approaches have proven effective for modeling structure at any depth (i.e., the seafloor, crust and mantle), and with the exception of thin-sheet modeling, can be applied to both broadband and long-period data. 
Example applications include mid-ocean ridge topography distortions (Key and Constable 2002) and continental shelf distortions (Heinson et al. 2005; Constable et al. 2009).

An alternative to the direct modeling approach is to assume the topography can be treated as a removable distortion (e.g., Heinson and Lilley 1993). In this approach, the difference in the electric and magnetic fields computed for models with and without the topography are used to strip the distortion from the data (e.g., Baba and Chave 2005). Matsuno et al. (2007) studied three different formulations of topographic correction equations and found the following to be the most robust:

$$
\mathbf{Z}_{\mathrm{c}}=(\mathbf{I}-\mathbf{M}) \mathbf{Z}_{0}\left(\mathbf{I}-\mathbf{K}_{\mathrm{e}} \mathbf{Z}_{0}\right)^{-1},
$$

where $\mathbf{Z}_{0}$ is the observed MT impedance tensor and $\mathbf{Z}_{\mathrm{c}}$ is the corrected (i.e., distortion free) tensor. $\mathbf{M}$ and $\mathbf{K}_{\mathrm{e}}$ are distortion tensors for the electric and magnetic fields that can be estimated using

$$
\begin{aligned}
\mathbf{E} & =\mathbf{E}_{\mathrm{m}}+\mathbf{M E}, \\
\mathbf{H} & =\mathbf{H}_{\mathrm{m}}+\mathbf{K}_{\mathrm{e}} \mathbf{E},
\end{aligned}
$$

where $\mathbf{E}_{\mathrm{m}}$ and $\mathbf{H}_{\mathrm{m}}$ are the undistorted electric and magnetic fields computed from a numerical model with a flat seafloor and $\mathbf{E}$ and $\mathbf{H}$ are the distorted fields computed with a model containing the topography. Matsuno et al. (2007) attribute the reliability of these equations to their close approximation to the theoretical integral equations for 3D EM (Hohmann 1975):

$$
\begin{aligned}
\mathbf{E}(\mathbf{r}) & =\mathbf{E}_{\mathrm{m}}(\mathbf{r})-i \omega \mu \int_{V} \delta \sigma(\mathbf{r}) \mathbf{G}\left(\mathbf{r}, \mathbf{r}^{\prime}\right) \mathbf{E}\left(\mathbf{r}^{\prime}\right) \mathrm{d} \mathbf{r}^{\prime} \\
\mathbf{H}(\mathbf{r}) & =\mathbf{H}_{\mathrm{m}}(\mathbf{r})+\nabla \times \int_{V} \delta \sigma(\mathbf{r}) \mathbf{G}\left(\mathbf{r}, \mathbf{r}^{\prime}\right) \mathbf{E}\left(\mathbf{r}^{\prime}\right) \mathrm{d} \mathbf{r}^{\prime}
\end{aligned}
$$

where $\mathbf{r}$ is a position vector, $\delta \sigma(\mathbf{r})$ is the anomalous topographic conductivity, and $\mathbf{G}\left(\mathbf{r}, \mathbf{r}^{\prime}\right)$ is the electromagnetic Green's tensor. An example application from Matsuno et al. (2007) is shown in Fig. 17. Other recent applications of topographic correction methods include: Baba et al. (2006), Seama et al. (2007), Ichiki et al. (2009), Shimizu et al. (2010) and Matsuno et al. (2010). While the correction method has proven particularly effective for long-period MT soundings in the deep ocean, further study is needed to determine if it can be successfully applied to the severe distortions observed in broadband data collected near coastlines, such as the San Diego Trough data shown in Fig. 16.

\subsection{Sedimentary Basin Characterization}

It has long been known that MT is useful for sedimentary basin exploration on land (e.g., Vozoff 1972), yet it was not until the advent of broadband marine instrumentation that high enough frequencies could be obtained for imaging offshore sedimentary basins (Constable et al. 1998). Early broadband applications centered around mapping resistive salt bodies in the Gulf of Mexico, where the MT result could be used to reduce the ambiguity in seismic interpretations of the subsalt sedimentary sequences (Hoversten et al. 1998; Constable et al. 1998; Hoversten et al. 2000). Figure 18 shows an example 2D model obtained from inversion of broadband data collected over the Gemini salt body in the Northern Gulf of Mexico (Key et al. 2006). A 3D inversion of the full array of 42 sites of Gemini MT data is 
(a)
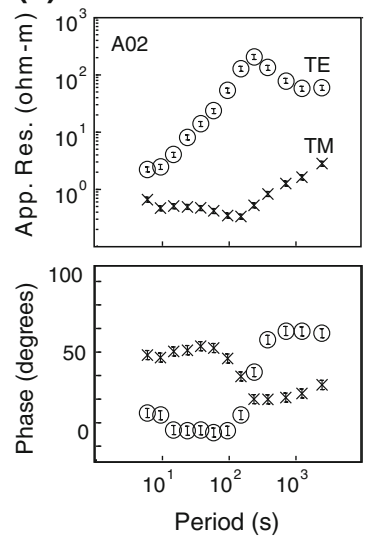

(c)

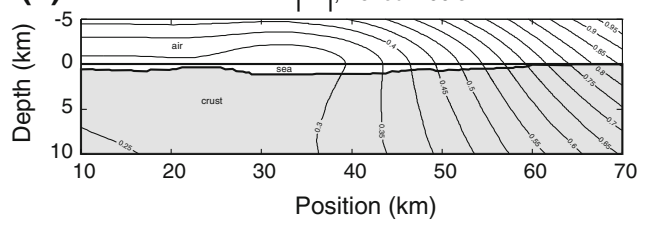

(b)
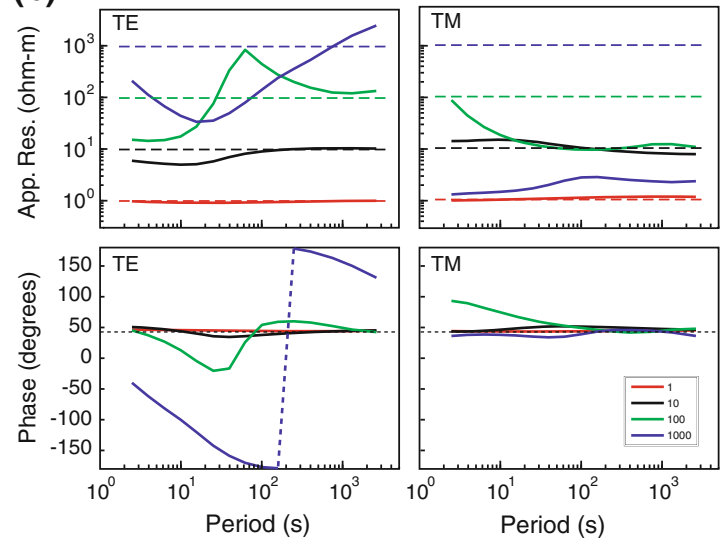

(d)

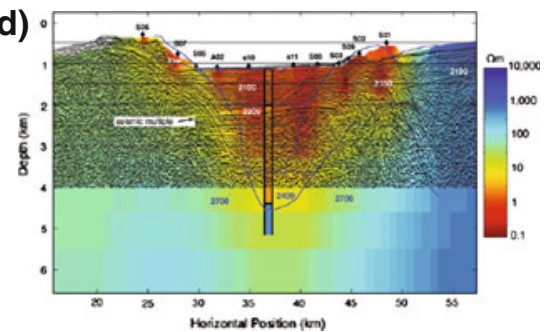

Fig. 16 Example of strong topographic and coastline distortion of marine MT data collected in the San Diego Trough offshore California (Constable et al. 2009). a Response from site A02 showing a cusp in TE resistivity, negative TE phases, and a strongly depressed TM mode. b Model responses for a bathmetry halfspace that includes the coastline topography, shown for the various seafloor resistivities indicated in the legend. Note the cusps and negative phases in the TE mode and the depressed TM mode, both of which arise from the coastline topography. c Contours of the TE electric field for a $100 \mathrm{ohm}-\mathrm{m}$ seafloor computed at 100 s period, showing electric field contours that correspond to TE magnetic field streamlines, illustrating a steepening associated with the coastline and local bathymetry. d Occam2DMT inversion model obtained with a finite element mesh that includes the coastline topography. A region of low resistivity agrees with a seismically imaged sedimentary basin in the Trough and low density detected by deep-tow gravity data

presented in Zhdanov et al. (2009). An example of the large-scale industrial application of marine MT is given in Wu et al. (2008), who report on 3D inversions of data from a $1,000+$ site broadband survey in the northern Gulf of Mexico, showing how massive receiver arrays can be used to map the salt geometry on a regional scale.

The MT responses from resistive salt bodies can often be quite subtle (e.g., Key et al. 2006). A more obvious use of marine MT is for mapping the thickness of sedimentary basins, where the large conductivity contrast between conductive porous sediments and deeper resistive basement gives rise to a significant increase in apparent resistivity at longer periods. The inversion of the San Diego Trough MT data shown in Fig. 16d provides an example of MT mapping the thickness of a conductive sedimentary basin surrounded by resistive basement. Similarly, the increase in resistivity associated with the basement at Gemini Prospect is clearly visible in Figs. 15 and 18.

Seismic imaging of sediments beneath basalt layers can be difficult due to strong reflections from the hard basalt that can obscure detection of deeper sedimentary structures. 


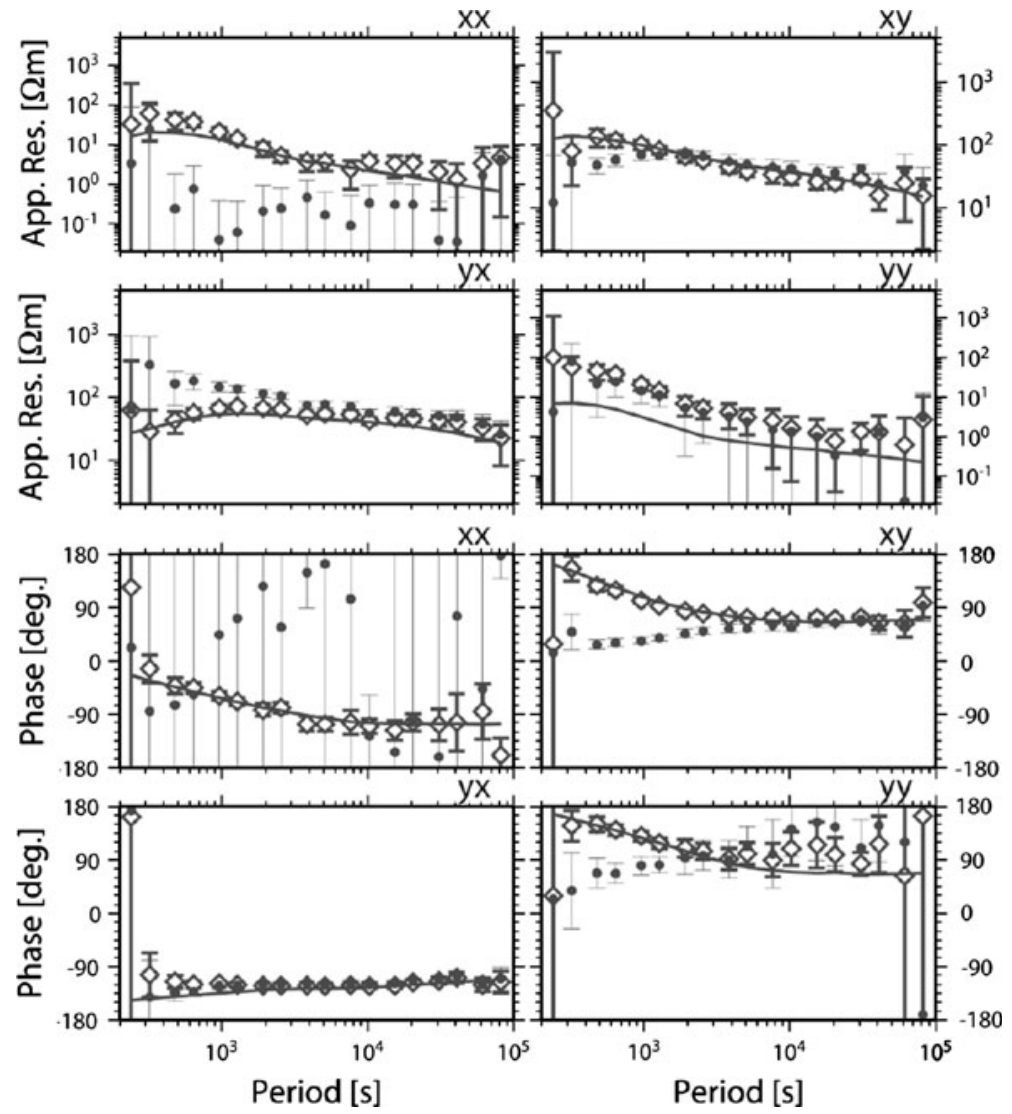

Fig. 17 Example of seafloor MT data before (diamonds) and after (dots) applying the correction in Eq. 2. The particular component of the impedance tensor is indicated above each plot. From Matsuno et al. (2007)

Jegen et al. (2009) present an use of marine MT for sub-basalt imaging off the Faroe Shelf, where joint inversion of gravity and MT data is used to detect a low resistivity zone interpreted to be sedimentary rich sequences (Fig. 19).

\subsection{Tectonic Studies}

While the past decade has seen the rapid rise of industrial marine EM, the use of MT for tectonic imaging has experienced its own period of growth (albeit at a less dramatic pace). Baba et al. (2006) present additional results from the MELT experiment to detect mantle upwelling beneath the spreading ridge on the southern East Pacific Rise. Longperiod MT data collected on a profile crossing the ridge to the north of the main profile shows no evidence for the conductive region immediately beneath the ridge that was seen to the south, suggesting along strike variations in melt production. High mantle conductivity observed east of the ridge is similar to the main profile and is attributed to anisotropic olivine with higher conductivity in the spreading direction. Key et al. (2005) documents a broadband MT survey farther to the north on the East Pacific Rise at $9^{\circ} \mathrm{N}$. 


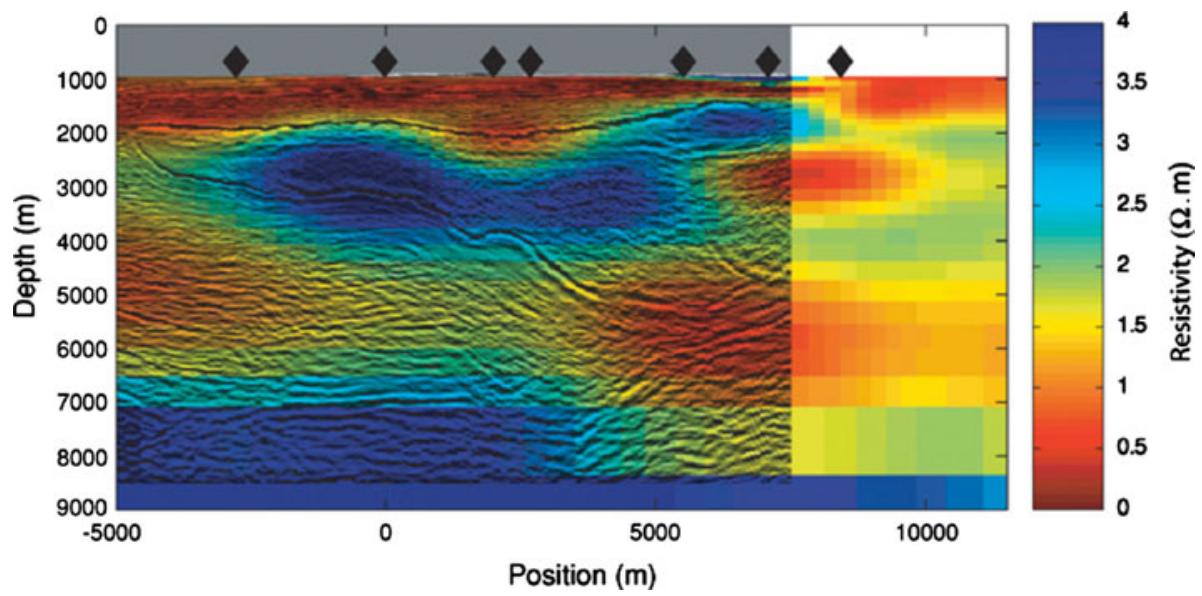

Fig. 18 Mapping a complex salt body with marine MT. Colors show resistivity from inversion of broadband seafloor MT responses from seven receivers (black diamonds). Black lines show depth-migrated reflections from a 3D seismic survey. Note the linear resistivity scale. From Key et al. (2006)

Toh et al. (2006b) present a 2D inversion of four long-period seafloor MT stations collected in the Japan Sea and four stations onshore Japan (Fig. 20). After topographic correction of the seafloor data, the inversion was performed with the poorly constrained resistive slab specified a priori as fixed structure, with the final inversion model revealing a deep conductive zone at $150-200 \mathrm{~km}$ depth immediately above the subducting slab. The high conductivity is thought to be evidence of slab transportation of hydrous minerals into the back-arc mantle. Seama et al. (2007) discuss a five station transect of long-period MT data collected in the Philippine Sea, finding a distinct low conductivity zone at depths of $50-150 \mathrm{~km}$ beneath the spreading axis of the Mariana Trough that may reflect deep melt processes associated with the mantle upwelling. Ichiki et al. (2009) provide a review of several onshore and offshore electrical conductivity studies beneath the northwestern Pacific, Japan and East Asia.

Matsuno et al. (2010) report on a multi-national MT survey across the central Mariana subduction system that targets the dynamics of the mantle wedge and slow-spreading backarc ridge (Fig. 21). Forty long-period MT stations deployed across the subduction system recorded for 9 months, yielding MT responses at 1,000-100,000 s. After topographic correction of the data, 2D inversions constrain a thick resistive lithosphere that is controlled by plate age in Pacific Ocean Basin but has constant thickness in Mariana Trough and Parece Vela Basin. Like the earlier study by Toh et al. (2006b), the geologically preferred models are found when a subducting slab is assumed a priori (see Fig. 21c-f). A conductive mantle observed beneath the uppermost resistive layer requires hydration of olivine and/or melting of the mantle. A resistive region beneath the volcanic arc down to $60 \mathrm{~km}$ suggests that any conductive fluids such as melt or free water are not well connected or are highly three-dimensional and of limited extent. Evidence for electrical anisotropy in the central Mariana upper mantle was found to be weak.

A highly unexpected result of recent surveys is that of Heinson et al. (2005) from the northwest Exmouth Plateau, a $500 \mathrm{~km}$ wide continental platform on the Northwest Shelf offshore Western Australia. This rifted margin has crustal thinning in excess of a factor of two or more that is thought to have been accommodated by significant lower crustal 


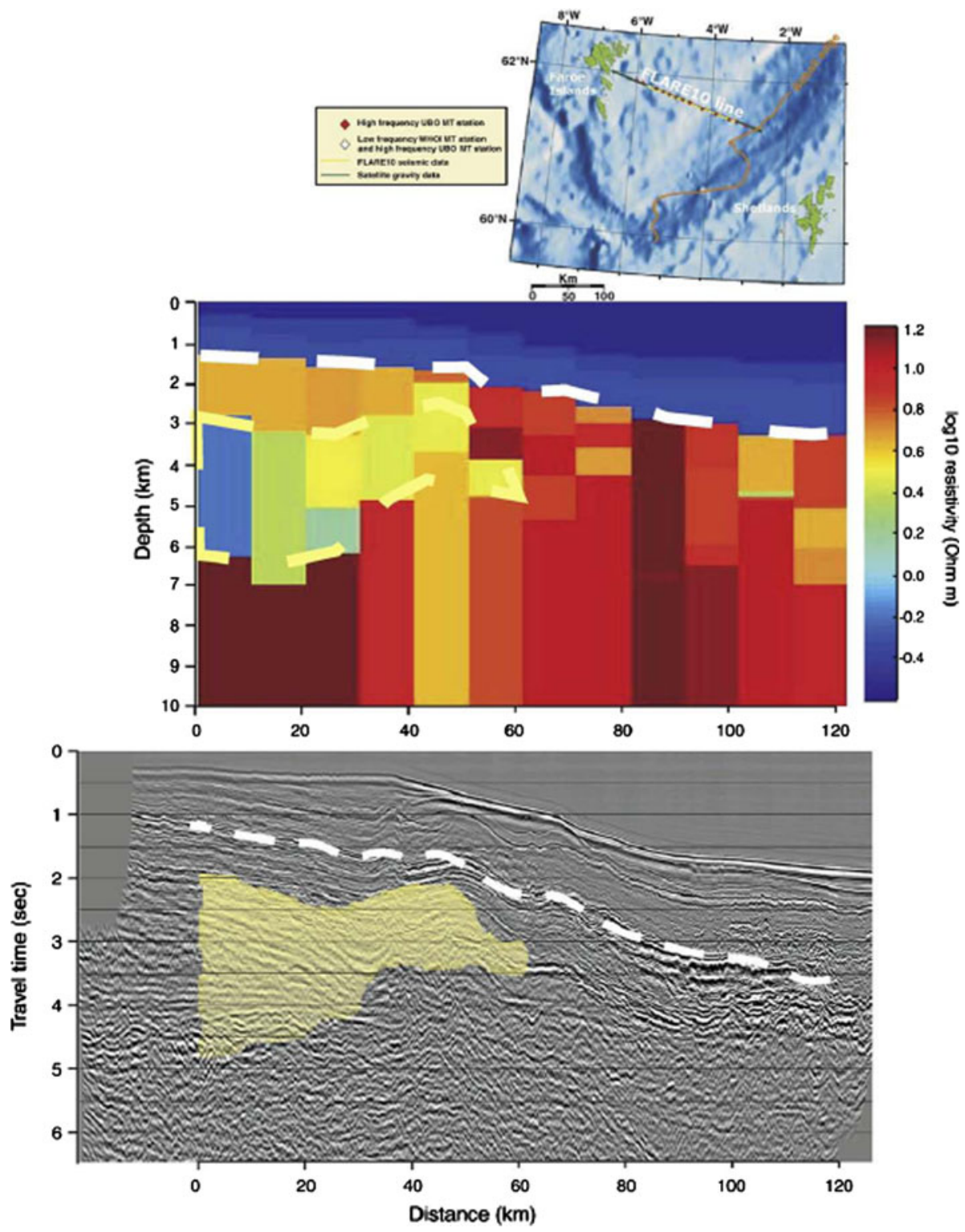

Fig. 19 An example of joint inversion of marine magnetotelluric and gravity data incorporating seismic constraints from sub-basalt imaging data collected off the Faroe Shelf (Jegen et al. 2009). The resistivity depth section was derived from 2D gravity/1D MT joint inversion; the yellow lines show a region of low resistivity interpreted to be caused by sedimentary rich sequences

extension. Using seafloor MT and GDS responses, they detected a highly conductive (10 $\mathrm{S} / \mathrm{m}$ ) region located at the depths of the lower crustal detachment zone (Fig. 22). The pronounced low in apparent resistivity at about 2,000 s period has been confirmed recently with 144 MT sites collected as part of the Scarborough gas field marine EM survey (Myer et al. 2010b). This conductive zone is intriguing since the depths are too deep for 
Fig. 20 Two-dimensional electrical section beneath the eastern margin of Japan Sea obtained from inversion of topography corrected data from four long-period seafloor MT stations and four additional land MT stations, from Toh et al. (2006b). The horizontal gray bar represents northeast Japan, while dots denote earthquake hypocenters. The resistive subducting slab was fixed in the inversion

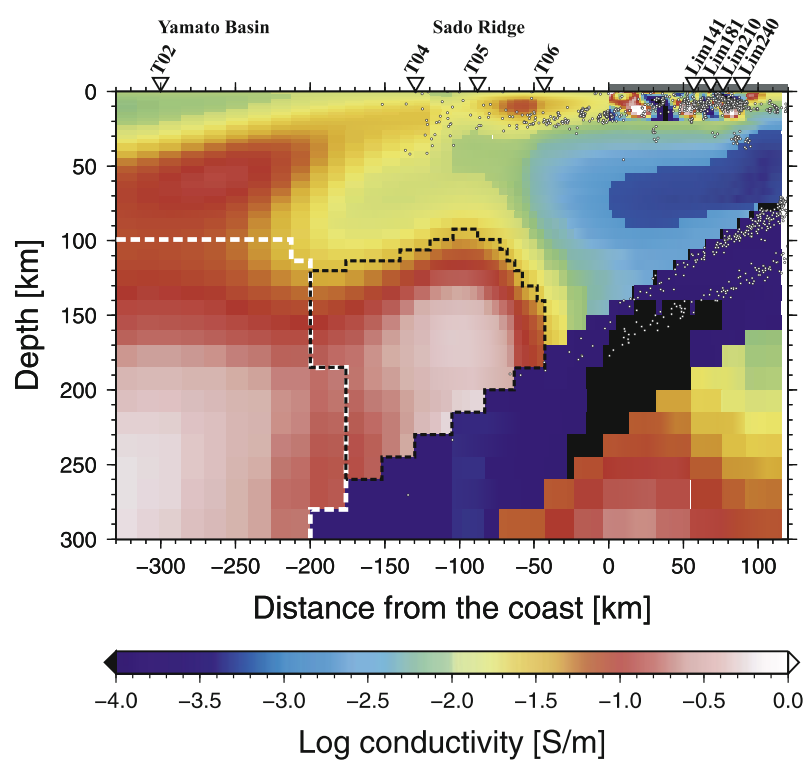

conductive saline brines, nor is the region is likely to contain conductive partial melt. Heinson et al. (2005) suggest that highly conducting graphite may line the lower crustal detachment zone, thereby facilitating extensional strain between the ductile and brittle zones of the crust. Future MT studies on other rifted margins are needed in order to learn if this significant conductor is a ubiquitous feature along detachment zones, and what implications this may have for our understanding of the kinematics of crustal extension.

\section{Where do we go from here?}

If the current pace of research continues into the future, linear extrapolation of the trends shown in Fig. 1 suggests that when the next marine EM review is given several years from now there may be well over 200 new papers and that the majority of these papers will cover industry relevant topics. The industrial use of marine EM has been driving many of the recent advances in our capabilities for large-scale data collection and multidimensional inversion using massively parallel computer systems; undoubtedly these capabilities will continue to see significant improvements in the near future. Our understanding of the physics of marine EM methods is likely to improve as issues such as topographic distortions, anisotropy, time versus frequency-domain methods, horizontal versus vertical transmitters and magnetic versus electric sources continue to be studied in the context of sensitivity, resolution and the economics of data collection for a variety of academic and industrial needs. One area in need of particular attention is the ability to quantify resolution (cf. sensitivity) in EM inversion models. Increasingly, large fleets of marine EM gear are being built for academic use; it is likely that many array CSEM and MT projects will be performed in the coming years, targeting the myriad of tectonic targets that have yet to be studied with electromagnetic methods. Another driving force for future discoveries will be the introduction of new talent to the marine EM community, as a perusal of the literature 

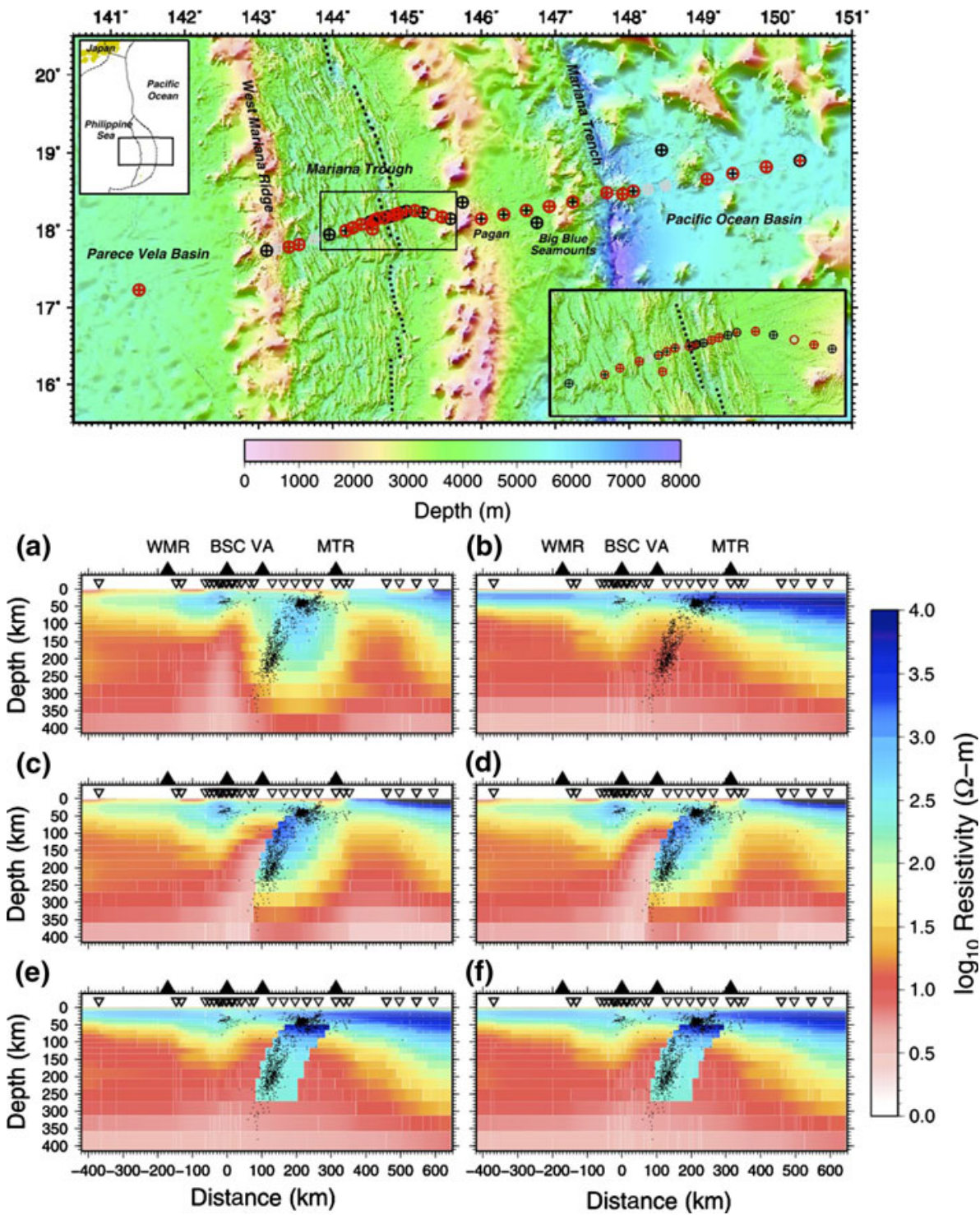

Fig. 21 Upper mantle electrical resistivity structure beneath the central Mariana subduction system, from Matsuno et al. (2010). A bathymetric map of the central Marianas showing the MT site locations (top). Red symbols denote data used in inversions, black symbols denote data which are not used in inversions, and gray symbols denote the locations where instruments were not recovered. Circles indicate magnetic field data and crosses indicate electric field data. The bottom panels shows inversion results computed using the TM responses and only the TE phases for: regularization with a different smoothing weights (a) and (b), and similarly with the addition of a break in regularization at the top of the subducting slab (c) and (d) and finally similar results when regularized against an a priori resistive slab model (e) and (d). See Matsuno et al. (2010) for further details

shows that a significant fraction of the recently published papers are from researchers new to our community, whether they are young researchers finishing their Ph.D. studies or are established researchers crossing over from other communities. 

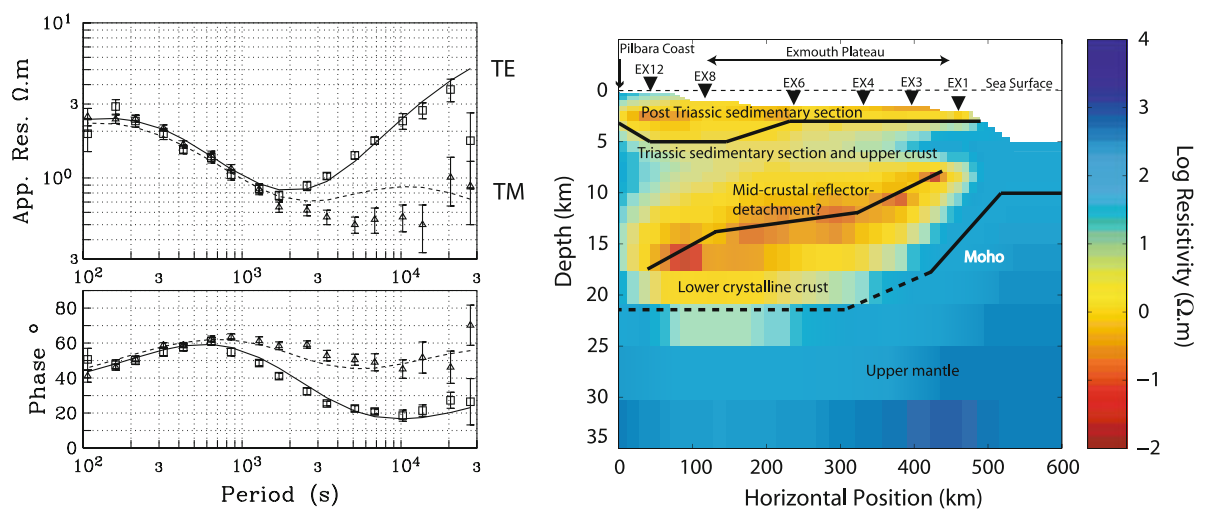

Fig. 22 Mapping a detachment zone conductor on the Northwest Shelf, Australia (Heinson et al. 2005). Left MT response from site EX6. Right Resistivity model obtained from an inversion of MT and GDS responses from the receivers shown as black triangles. The prominent mid-crustal conductor was recently confirmed by 144 broadband MT stations collected in May-June 2009 at Scarborough gas field, located approximately between stations EX3 and EX4 (Myer et al. 2010b)

Acknowledgments I am grateful to Prof. Yasuo Ogawa and the Organizing Committee of the 20th Workshop on Electromagnetic Induction in the Earth in Giza, Egypt, for the invitation to prepare this review. I am indebted to Steven Constable for the invitation to participate in my first marine EM research cruise in 1997, where coincidently I was told by another colleague that I should instead pursue a PhD in seismology since there would be no future in marine EM! Chip Cox is thanked for providing valuable reprints of some of the earliest marine EM papers. This work was supported by the Seafloor Electromagnetic Methods Consortium at Scripps Institution of Oceanography.

\section{References}

Abubakar A, Habashy TM, Druskin VL, Knizhnerman L, Alumbaugh D (2008) 2.5D forward and inverse modeling for interpreting low-frequency electromagnetic measurements. Geophysics 73(4):F165F177. doi:10.1190/1.2937466

Amundsen L, Loseth L, Mittet R, Ellingsrud S, Ursin B (2006) Decomposition of electromagnetic fields into upgoing and downgoing components. Geophysics 71(5):G211-G223

Andreis D, MacGregor L (2008) Controlled-source electromagnetic sounding in shallow water: principles and applications. Geophysics 73(1):F21-F32. doi:10.1190/1.2815721

Baba K (2005) Electrical structure in marine tectonic settings. Surv Geophys 26(6):701-731

Baba K, Chave AD (2005) Correction of seafloor magnetotelluric data for topographic effects during inversion. J Geophys Res 110:B12105. doi:10.1029/2004JB003463

Baba K, Seama N (2002) New technique for the incorporation of seafloor topography in electromagnetic modelling. Geophys J Int 150(2):392-420

Baba K, Tarits P, Chave AD, Evans RL, Hirth G, Mackie RL (2006) Electrical structure beneath the northern MELT line on the East Pacific Rise at 15 degrees 45'S. Geophys Res Lett 33(22):L22,301

Bannister P (1968) Determination of electrical conductivity of sea bed in shallow waters. Geophysics 33(6):995

Bhuyian AH, Thrane BP, Landro M, Johansen SE (2010) Controlled source electromagnetic three-dimensional grid-modelling based on a complex resistivity structure of the seafloor: effects of acquisition parameters and geometry of multi-layered resistors. Geophys Prospect 58(3):505-533. doi:10.1111/ j.1365-2478.2009.00844.x, notes

Börner RU, Ernst O, Spitzer K (2008) Fast 3-D simulation of transient electromagnetic fields by model reduction in the frequency domain using Krylov subspace projection. Geophys J Int 173(3):766-780

Brown C (1994) Tectonic interpretation of regional conductivity anomalies. Surv Geophys 15(2):123-157

Chave AD (2009) On the electromagnetic fields produced by marine frequency domain controlled sources. Geophys J Int 179(3):1429-1457. doi:10.1111/j.1365-246X.2009.04367.x 
Chave AD, Cox C (1982) Controlled electromagnetic sources for measuring electrical-conductivity beneath the oceans. 1. Forward problem and model study. J Geophys Res 87:5327-5338

Chave A, Constable S, Edwards RN (1991) Electrical exploration methods for the seafloor. In: Nabighian MN (ed) Electromagnetic methods in applied geophysics. Society of Exploration Geophysicists, Tulsa, pp 931-966

Cheesman SJ, Edwards RN, Chave AD (1987) On the theory of sea-floor conductivity mapping using transient electromagnetic systems. Geophysics 52(02):204-217

Chen J, Hoversten GM, Vasco D, Rubin Y, Hou Z (2007) A Bayesian model for gas saturation estimation using marine seismic AVA and CSEM data. Geophysics 72(2):WA85-WA95. doi:10.1190/1.2435082

Christensen NB, Dodds K (2007) 1D inversion and resolution analysis of marine CSEM data. Geophysics 72(2):WA27-WA38. doi:10.1190/1.2437092

Commer M, Newman GA (2009) Three-dimensional controlled-source electromagnetic and magnetotelluric joint inversion. Geophys J Int 178(3):1305-1316. doi:10.1111/j.1365-246X.2009.04216.X

Commer M, Newman GA, Carazzone J, Dickens TA, Green KE, Wahrmund LA, Willen DE, Shiu J (2008) Massively parallel electrical-conductivity imaging of hydrocarbons using the IBM Blue Gene/L supercomputer. IBM J Res Dev 52(1-2):93-103

Constable S (2010) Ten years of marine CSEM for hydrocarbon exploration. Geophysics 75(5):75A6775A81, notes

Constable S, Srnka LJ (2007) An introduction to marine controlled-source electromagnetic methods for hydrocarbon exploration. Geophysics 72(2):WA3-WA12

Constable S, Weiss CJ (2006) Mapping thin resistors and hydrocarbons with marine EM methods: insights from 1D modeling. Geophysics 71(2):G43-G51

Constable S, Key K, Lewis L (2009) Mapping offshore sedimentary structure using electromagnetic methods and terrain effects in marine magnetotelluric data. Geophys J Int 176(2):431-442. doi: 10.1111/j.1365-246X.2008.03975.x

Constable SC (1990) Marine electromagnetic induction studies. Surv Geophys 11:303-327

Constable SC, Orange AS, Hoversten GM, Morrison HF (1998) Marine magnetotellurics for petroleum exploration part I: a sea-floor equipment system. Geophysics 63(03):816-825

Cox C (1980) Electromagnetic induction in the oceans and inferences on the constitution of the earth. Geophys Surv 4:137-156

Cox C (1981) On the electrical-conductivity of the oceanic lithosphere. Phys Earth Planet In 25(3):196-201

Cox C, Teramoto T, Filloux J (1964) On coherent electric and magnetic fluctuations in the sea. In: Yoshida K (ed) Studies on Oceanography, Tokyo, pp 449-457

Cox C, Deaton T, Pistek P (1981) An active source EM method for the seafloor. Scripps Institution of Oceanography technical report. http://escholarship.org/uc/item/7dr96489. Accessed 25 May 2010

Darnet M, Choo MCK, Plessix RE, Rosenquist ML, Yip-Cheong K, Sims E, Voon JWK (2007) Detecting hydrocarbon reservoirs from CSEM data in complex settings: application to deepwater Sabah, Malaysia. Geophysics 72(2):WA97-WA103. doi:10.1190/1.2435201

Dell'Aversana P, Vivier M (2009) Expanding the frequency spectrum in marine CSEM applications. Geophys Prospect 57(4):573-590. doi:10.1111/j.1365-2478.2008.00777.x

Edwards N (2005) Marine controlled source electromagnetics: principles, methodologies, future commercial applications. Surv Geophys 26(6):675-700

Edwards RN, Law L, DeLaurier J (1981) On measuring the electrical conductivity of the oceanic crust by a modified magnetometric resistivity method. J Geophys Res 86:11,609-11,615

Eidesmo T, Ellingsrud S, MacGregor L, Constable S, Sinha M, Johansen S, Kong F, Westerdahl H (2002) Sea bed logging (SBL), a new method for remote and direct identification of hydrocarbon filled layers in deepwater areas. First Break 20:144-152

Ellingsrud S, Eidesmo T, Johansen S, Sinha M, MacGregor L, Constable S (2002) Remote sensing of hydrocarbon layers by seabed logging (SBL): results from a cruise offshore Angola. Lead Edge 21:972-982

Ellis M, Evans RL, Hutchinson D, Hart P, Gardner J, Hagen R (2008) Electromagnetic surveying of seafloor mounds in the northern Gulf of Mexico. Mar Petroleum Geol 25(9):960-968. doi:10.1016/j.marpetgeo. 2007.12.006

Evans RL (2007) Using CSEM techniques to map the shallow section of seafloor: from the coastline to the edges of the continental slope. Geophysics 72(2):WA105-WA116. doi:10.1190/1.2434798

Evans RL, Constable SC, Sinha MC, Cox CS, Unsworth MJ (1991) Upper crustal resistivity structure of the East Pacific Rise near $13^{\circ}$ N. Geophys Res Lett 18:1917-1920

Evans RL, Webb SC, Crawford W, Golden C, Key K, Lewis L, Miyano H, Roosen E, Doherty D (2002) Crustal resistivity structure at $9^{\circ} 50^{\prime} \mathrm{N}$ on the East Pacific Rise: results of an electromagnetic survey. Geophys Res Lett 29(6):6-1-6-4 
Evans RL, Escartin J, Cannat M (2010) A short electromagnetic profile across the Kane oceanic core complex. Geophys Res Lett 37:L15,309. doi:10.1029/2010GL043813

Fan Y, Snieder R, Slob E, Hunziker J, Singer J, Sheiman J, Rosenquist M (2010) Synthetic aperture controlled source electromagnetics. Geophys Res Lett 37:L13,305. doi:10.1029/2010GL043981

Filloux JH (1967) An ocean-bottom D-component magnetometer. Geophysics 32(06):978-987

Filloux JH (1973) Techniques and instrumentation for study of natural electromagnetic induction at sea. Phys Earth Planet In 7(3):323-338

Filloux JH (1979) Magnetotelluric and related electromagnetic investigations in geophysics. Rev Geophys 17:282-294

Fischer G, Weaver J (1986) Theoretical investigation of the ocean coast effect at a passive continentalmargin. Phys Earth Planet In 42(4):246-254

Fonarev G (1982) Electromagnetic research in the ocean. Geophys Surv 4(4):501-508

Franke A, Börner RU, Spitzer K (2007) Adaptive unstructured grid finite element simulation of twodimensional magnetotelluric fields for arbitrary surface and seafloor topography. Geophys J Int 171(1):71-86. doi:10.1111/j.1365-246x.2007.03481.x

Gallardo LA, Meju MA (2007) Joint two-dimensional cross-gradient imaging of magnetotelluric and seismic traveltime data for structural and lithological classification. Geophys J Int 169(3):1261-1272

Goto T, Kasaya T, Machiyama H, Takagi R, Matsumoto R, Okuda Y, Satoh M, Watanabe T, Seama N, Mikada H, Sanada Y, Kinoshita M (2008) A marine deep-towed DC resistivity survey in a methane hydrate area, Japan Sea. Explor Geophys 39(1):52-59. doi:10.1071/EG08003

Heinson G (1999) Electromagnetic studies of the lithosphere and asthenosphere. Surv Geophys 20:229-255. doi:10.1023/A:1006689521329

Heinson G, Constable S (1992) The electrical conductivity of the oceanic upper mantle. Geophys J Int 110:159-179

Heinson G, Lilley F (1993) An application of thin-sheet electromagnetic modelling to the Tasman Sea. Phys Earth Planet In 81:231-251

Heinson G, White A, Lilley FEM (2005) Rifting of a passive margin and development of a lower-crustal detachment zone: evidence from marine magnetotellurics. Geophys Res Lett 32(12):L12,305

Hohmann GW (1975) Three-dimensional induced-polarization and electromagnetic modeling. Geophysics 40(02):309-324, errata in GEO-50-11-2279

Hoversten GM, Morrison HF, Constable SC (1998) Marine magnetotellurics for petroleum exploration, part II: numerical analysis of subsalt resolution. Geophysics 63(03):826-840

Hoversten GM, Constable SC, Morrison HF (2000) Marine magnetotellurics for base-of-salt mapping: Gulf of Mexico field test at the Gemini structure. Geophysics 65(5):1476-1488

Hoversten GM, Cassassuce F, Gasperikova E, Newman GA, Chen JS, Rubin Y, Hou ZS, Vasco D (2006) Direct reservoir parameter estimation using joint inversion of marine seismic AVA and CSEM data. Geophysics 71(3):C1-C13

Hu W, Abubakar A, Habashy TM (2009) Joint electromagnetic and seismic inversion using structural constraints. Geophysics 74(6):R99-R109. doi:10.1190/1.3246586

Ichiki M, Baba K, Toh H, Fuji-ta K (2009) An overview of electrical conductivity structures of the crust and upper mantle beneath the northwestern Pacific, the Japanese islands, and continental East Asia. Gondwana Res 16(3-4):545-562. doi:10.1016/j.gr.2009.04.007

Jegen MD, Hobbs RW, Tarits P, Chave A (2009) Joint inversion of marine magnetotelluric and gravity data incorporating seismic constraints preliminary results of sub-basalt imaging off the Faroe Shelf. Earth Planet Sci Lett 282(1-4):47-55. doi:10.1016/j.eps1.2009.02.018

Key K (2003) Application of broadband marine magnetotelluric exploration to a 3D salt structure and a fast spreading ridge. PhD thesis, University of California, San Diego

Key K (2009) 1D inversion of multicomponent, multifrequency marine CSEM data: methodology and synthetic studies for resolving thin resistive layers. Geophysics 74(2):F9-F20. doi:10.1190/1.3058434

Key K, Constable S (2002) Broadband marine MT exploration of the East Pacific Rise at $9^{\circ} 50^{\prime} \mathrm{N}$. Geophys Res Lett 29(22):11-1-11-4

Key K, Lockwood A (2010) Determining the orientation of marine CSEM receivers using orthogonal Procrustes rotation analysis. Geophysics 75(3):F63-F70. doi:10.1190/1.3378765

Key K, Weiss C (2006) Adaptive finite element modeling using unstructured grids: the 2D magnetotelluric example. Geophysics 71(6):G291-G299

Key K, Constable S, Behrens J, Heinson G, Weiss C (2005) Mapping the northern EPR magmatic system using marine EM. Ridge 2000 Events 3:35-37

Key KW, Constable SC, Weiss CJ (2006) Mapping 3D salt using the 2D marine magnetotelluric method: case study from Gemini prospect, Gulf of Mexico. Geophysics 71(1):B17-B27 
Kong FN, Johnstad SE, Rosten T, Westerdahl H (2008) A 2.5d finite-element-modeling difference method for marine CSEM modeling in stratified anisotropic media. Geophysics 73(1):F9-F19. doi: $10.1190 / 1.2819691$

Kong FN, Roth F, Olsen PA, Stalheim SO (2009) Casing effects in the sea-to-borehole electromagnetic method. Geophysics 74(5):F77-F87. doi:10.1190/1.3173807

Kong FN, Johnstad SE, Park J (2010) Wavenumber of the guided wave supported by a thin resistive layer in marine controlled-source electromagnetics. Geophys Prospect 58(4):711-723. doi:10.1111/j.13652478.2009.00860.x

Larsen J, Cox C (1966) Lunar and solar daily variation in magnetotelluric field beneath ocean. J Geophys Res 71(18):4441-4445

Law L (1983) Marine electromagnetic research. Surv Geophys 6:123-135

Li M, Abubakar A, Habashy TM, Zhang Y (2010) Inversion of controlled-source electromagnetic data using a model-based approach. Geophys Prospect 58(3):455-467. doi:10.1111/j.1365-2478.2009.0824.x

Li S, Booker JR, Aprea C (2008) Inversion of magnetotelluric data in the presence of strong bathymetry/ topography. Geophys Prospect 56(2):259-268

Li Y, Constable S (2007) 2D marine controlled-source electromagnetic modeling: part 2-the effect of bathymetry. Geophysics 72(2):WA63-WA71

Li Y, Key K (2007) 2D marine controlled-source electromagnetic modeling: part 1-an adaptive finite element algorithm. Geophysics 72(2):WA51-WA62

Li YG, Constable S (2010) Transient electromagnetic in shallow water: insights from 1D modeling. Chin J Geophys Ch 53(3):737-742. doi:10.3969/j.issn.0001-5733.2010.03.029

Lien M, Mannseth T (2008) Sensitivity study of marine CSEM data for reservoir production monitoring. Geophysics 73(4):F151-F163. doi:10.1190/1.2938512

Løseth L, Pedersen HM, Ursin B, Amundsen L, Ellingsrud S (2006) Low-frequency electromagnetic fields in applied geophysics: waves or diffusion? Geophysics 71(4):W29-W40

Løseth LO, Ursin B (2007) Electromagnetic fields in planarly layered anisotropic media. Geophys J Int 170(1):44-80

MacGregor LM, Sinha M, Constable S (2001) Electrical resistivity structure of the Valu Fa Ridge, Lau Basin, from marine controlled-source electromagnetic sounding. Geophys J Int 146:217-236

Matsuno T, Seama N, Baba K (2007) A study on correction equations for the effect of seafloor topography on ocean bottom magnetotelluric data. Earth Planets Space 59(8):981-986

Matsuno T, Seama N, Evans R, Chave A, Baba K, White A, Goto T, Heinson G, Boren G, Yoneda A, Utada H (2010) Upper mantle electrical resistivity structure beneath the central Mariana subduction system. Geochem Geophys Geosyst 11(9):Q09-Q003

Mattsson J, Lund L, Lima J, Engelmark F, McKay A (2010) Case study: a towed EM test at the Peon discovery in the North Sea. In: EAGE meeting. pp 1-5, notes

Mittet R (2010) High-order finite-difference simulations of marine CSEM surveys using a correspondence principle for wave and diffusion fields. Geophysics 75(1):F33-F50. doi:10.1190/1.3278525

Mittet R, Schaug-Pettersen T (2008) Shaping optimal transmitter waveforms for marine CSEM surveys. Geophysics 73(3):F97-F104. doi:10.1190/1.2898410

Mittet R, Aakervik OM, Jensen HR, Ellingsrud S, Stovas A (2007) On the orientation and absolute phase of marine CSEM receivers. Geophysics 72(4):F145-F155. doi:10.1190/1.2732556

Mulder WA (2006) A multigrid solver for 3D electromagnetic diffusion. Geophys Prospect 54(5):633-649

Myer D, Constable S, Key K (2010a) A marine EM survey of the Scarborough gas field, Northwest Shelf of Australia. First Break 28:77-82

Myer D, Constable S, Key K (2010b) A marine MT and CSEM survey of the Scarborough gas field on the Exmouth Plateau. In: IAGA WG 1-2 on electromagnetic induction in the earth 20th workshop abstract. pp $1-4$, notes

Newman GA, Commer M, Carazzone JJ (2010) Imaging CSEM data in the presence of electrical anisotropy. Geophysics 75(2):F51-F61. doi:10.1190/1.3295883

Nordskag JI, Amundsen L (2007) Asymptotic airwave modeling for marine controlled-source electromagnetic surveying. Geophysics 72(6):F249-F255. doi:10.1190/1.2786025

Nordskag JI, Amundsen L, Loseth L, Holvik E (2009) Elimination of the water-layer response from multicomponent source and receiver marine electromagnetic data. Geophys Prospect 57(5):897-918. doi: 10.1111/j.1365-2478.2008.00758.x

Orange A, Key K, Constable S (2009) The feasibility of reservoir monitoring using time-lapse marine CSEM. Geophysics 74(2):F21-F29. doi:10.1190/1.3059600

Palshin N (1996) Oceanic electromagnetic studies: a review. Surv Geophys 17(4):455-491

Parker RL (1994) Geophysical inverse theory. Princeton University Press, Princeton 
Plessix RE, Mulder WA (2008) Resistivity imaging with controlled-source electromagnetic data: depth and data weighting. Inverse Probl 24(3):034,012. doi:10.1088/0266-5611/24/3/034012

Plessix RE, Darnet M, Mulder WA (2007) An approach for 3D multisource, multifrequency CSEM modeling. Geophysics 72(5):SM177-SM184. doi:10.1190/1.2744234

Ramananjaona C, MacGregor L, Andréis D (2011) Sensitivity and inversion of marine electromagnetic data in a vertically anisotropic stratified earth. Geophys Prospect 59(2):341-360. doi:10.1111/j.1365-2478. 2010.00919.x, notes

Sasaki Y, Meju MA (2009) Useful characteristics of shallow and deep marine CSEM responses inferred from 3D finite-difference modeling. Geophysics 74(5):F67-F76. doi:10.1190/1.3168616

Scholl C, Edwards RN (2007) Marine downhole to seafloor dipole-dipole electromagnetic methods and the resolution of resistive targets. Geophysics 72(2):WA39-WA49. doi:10.1190/1.2434775

Schwalenberg K, Edwards RN (2004) The effect of seafloor topography on magnetotelluric fields: an analytic formulation confirmed with numerical results. Geophys J Int 159:607-621

Schwalenberg K, Willoughby E, Mir R, Edwards RN (2005) Marine gas hydrate electromagnetic signatures in Cascadia and their correlation with seismic blank zones. First Break 23:57-63

Schwalenberg K, Haeckel M, Poort J, Jegen M (2010a) Evaluation of gas hydrate deposits in an active seep area using marine controlled source electromagnetics: results from Opouawe Bank, Hikurangi Margin, New Zealand. Mar Geol 272:79-88

Schwalenberg K, Wood W, Pecher I, Hamdan L, Henrys S, Jegen M, Coffin R (2010b) Preliminary interpretation of electromagnetic, heat flow, seismic, and geochemical data for gas hydrate distribution across the Porangahau Ridge, New Zealand. Mar Geol 272(1-4):89-98. doi:10.1016/j.margeo. 2009.10.024

Seama N, Baba K, Utada H, Toh H, Tada N, Ichiki M, Matsuno T (2007) 1-d electrical conductivity structure beneath the Philippine Sea: results from an ocean bottom magnetotelluric survey. Phys Earth Planet In 162(1-2):2-12. doi:10.1016/j.pepi.2007.02.014

Shimizu H, Koyama T, Baba K, Utada H (2010) Revised 1-D mantle electrical conductivity structure beneath the north Pacific. Geophys J Int 180(3):1030-1048. doi:10.1111/j.1365-246X.2009.04466.x

Singer BS (2008) Electromagnetic integral equation approach based on contraction operator and solution optimization in Krylov subspace. Geophys J Int 175(3):857-884. doi:10.1111/j.1365-246X.2008. 03930.x

Sinha M, Constable S, Peirce C, White A, Heinson G, MacGregor L, Navin D (1998) Magmatic processes at slow spreading ridges: implications of the RAMESSES experiment at $57^{\circ} 45^{\prime} \mathrm{N}$ on the Mid-Atlantic Ridge. Geophys J Int 135(3):731-745

Smith T, Hoversten M, Gasperikova E, Morrison F (1999) Sharp boundary inversion of 2D magnetotelluric data. Geophys Prospect 47(4):469-486, errata in GPR-47-6-1120

Stratton JA (1941) Electromagnetic theory. McGraw-Hill, New York

Streich R (2009) 3D finite-difference frequency-domain modeling of controlled-source electromagnetic data: direct solution and optimization for high accuracy. Geophysics 74(5):F95-F105. doi: $10.1190 / 1.3196241$

Tada N, Seama N, Goto T, Kido M (2005) 1-D resistivity structures of the oceanic crust around the hydrothermal circulation system in the central Mariana Trough using magnetometric resistivity method. Earth Planets Space 57(7):673-677

Toh H, Hamano Y, Ichiki M (2006a) Long-term seafloor geomagnetic station in the northwest Pacific: a possible candidate for a seafloor geomagnetic observatory. Earth Planets Space 58:697-705

Toh H, Baba K, Ichiki M, Motobayashi T, Ogawa Y, Mishina M, Takahashi I (2006b) Two-dimensional electrical section beneath the eastern margin of Japan Sea. Geophys Res Lett 33(22):L22,309. doi: 10.1029/2006GL027435

Toh H, Hamano Y, Goto T, Utada H (2010) Long-term seafloor electromagnetic observation in the northwest pacific may detect the vector geomagnetic secular variation. Data Sci J 9:IGY100-IGY109

Ueda T, Zhdanov MS (2008) Fast numerical methods for marine controlled-source electromagnetic (EM) survey data based on multigrid quasi-linear approximation and iterative EM migration. Explor Geophys 39(1):60-67. doi:10.1071/EG08002

Um ES, Alumbaugh DL (2007) On the physics of the marine controlled-source electromagnetic method. Geophysics 72(2):WA13-WA26. doi:10.1190/1.2432482

Vozoff K (1972) The magnetotelluric method in the exploration of sedimentary basins. Geophysics 37:98-141

Weidelt P (2007) Guided waves in marine CSEM. Geophys J Int 171(1):153-176. doi:10.1111/j.1365-246X. 2007.03527.x

Weiss C (2007) The fallacy of the "shallow-water problem" in marine CSEM exploration. Geophysics 72(6):A93-A97 
Weiss CJ, Constable S (2006) Mapping thin resistors in the marine environment, part II: modeling and analysis in 3D. Geophysics 71(6):G321-G332

Weitemeyer K (2008) Marine electromagnetic methods for gas hydrate characterization. $\mathrm{PhD}$ thesis, University of California, San Diego

Weitemeyer K, Constable S, Key K, Behrens J (2006) First results from a marine controlled-source electromagnetic survey to detect gas hydrates offshore Oregon. Geophys Res Lett 33(L03304). doi: $10.1029 / 2005$ GL024896

Wertheim G (1953) Studies of the electric potential between Key West, Florida, and Havana, Cuba, Technical report submitted to the Office of Naval Research, Unpublished Manuscript

Wu X, Sandberg S, Roper T (2008) Three-dimensional marine magnetotelluric resolution for subsalt imaging and case study in the Gulf of Mexico. SEG Tech Program Expand Abstr 27(1):574-578. doi: $10.1190 / 1.3063718$, notes

Young PD, Cox CS (1981) Electromagnetic active source sounding near the East Pacific Rise. Geophys Res Lett 8:1043-1046

Zach JJ, Brauti K (2009) Methane hydrates in controlled-source electromagnetic surveys-analysis of a recent data example. Geophys Prospect 57(4):601-614. doi:10.1111/j.1365-2478.2009.00809.x

Zhdanov MS, Wan L, Gribenko A, Cuma M, Key K, Constable S (2009) Rigorous 3D inversion of marine magnetotelluric data in the area with complex bathymetry. SEG Tech Program Expand Abstr 28(1):729-733. doi:10.1190/1.3255858

Ziolkowski A, Parr R, Wright D, Nockles V, Limond C, Morris E, Linfoot J (2010) Multi-transient electromagnetic repeatability experiment over the North Sea Harding field. Geophys Prospect 58(6):11591176. doi:10.1111/j.1365-2478.2010.00882.x 